\author{
Federal Reserve Bank of New York \\ Staff Reports
}

\title{
Business Cycle Fluctuations and the Distribution of Consumption
}

\author{
Giacomo De Giorgi \\ Luca Gambetti
}

Staff Report No. 716

March 2015

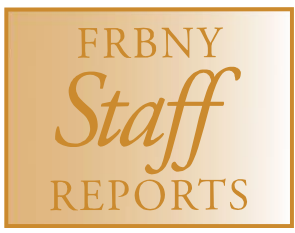

This paper presents preliminary findings and is being distributed to economists and other interested readers solely to stimulate discussion and elicit comments. The views expressed in this paper are those of the authors and do not necessarily reflect the position of the Federal Reserve Bank of New York or the Federal Reserve System. Any errors or omissions are the responsibility of the authors. 


\author{
Business Cycle Fluctuations and the Distribution of Consumption \\ Giacomo De Giorgi and Luca Gambetti \\ Federal Reserve Bank of New York Staff Reports, no. 716 \\ March 2015 \\ JEL classification: C3, D12, E21, E63
}

\begin{abstract}
This paper sheds new light on the interactions between business cycles and the consumption distribution. We use Consumer Expenditure Survey data and a factor model to characterize the cyclical dynamics of the consumption distribution. We first establish that our approach is able to closely match business cycle fluctuations of consumption from the National Account. We then study the responses of the consumption distribution to total factor productivity shocks and economic policy uncertainty shocks. Importantly, we find that the responses of the right tail of the consumption distribution, mostly comprising more highly educated individuals, to shocks that drive cyclical fluctuations are larger and quicker than in other parts of the distribution. We note that the cost of business cycle fluctuations is larger than that found using aggregate consumption and that the shocks we analyze reduce consumption inequality on impact.
\end{abstract}

Key words: consumption, inequality, cost of business cycles, heterogeneity, aggregate shocks, structural factor model, FAVAR

De Giorgi: Federal Reserve Bank of New York (e-mail: giacomo.degiorgi@ny.frb.org). Gambetti: Universitat Autònoma de Barcelona and Barcelona Graduate School of Economics (e-mail: luca.gambetti@uab.cat). The authors thank Rodica Calmuc and Michela Giorcelli for very skillful research assistance. Financial support from the Spanish Ministry of Science and Innovation through grant ECO2009-09847 and the Barcelona Graduate School Research Network is gratefully acknowledged. De Giorgi acknowledges financial support from the Spanish Ministry of Economy and Competitiveness, through the Severo Ochoa Programme for Centres of Excellence in R\&D (SEV-2011-0075) and ECO2011-28822, and the EU through the Marie Curie CIG grant FP7-631510. The views expressed in this paper are those of the authors and do not necessarily reflect the position of the Federal Reserve Bank of New York or the Federal Reserve System. 


\section{Introduction}

How does the consumption distribution evolve over the business cycle? How do shocks that drive economic fluctuations affect the consumption distribution? What are the cyclical properties of consumption inequality? Is exposure to the business cycle different across consumers? Answering these questions is a priority for the design of sensible and effective economic policies. Indeed in recent years several authors have stressed the importance of going beyond the representative agent framework by allowing some type of heterogeneity across consumers for meaningful welfare analysis (for a review, see Heathcote, Storesletten and Violante, 2009, Guvenen, 2011). Krusell, Mukoyama, Sahin, and Smith (2009), using a calibrated model for the US, show that the cost of business cycles is substantially different across consumers: very poor and rich consumers would gain substantially more than other consumers from the removal of cyclical fluctuations.

On the empirical front there is a substantial amount of work documenting trends in economic inequality, see for example Heathcote, Perri and Violante (2010a) and the literature cited therein. In that paper the authors analyze long run trends of inequality in wages, income and consumption over the last four decades in the US and show that the increase in consumption inequality has been much more moderate than that of wages and disposable incomes. A more recent literature finds that consumption inequality tracks income inequality more closely than previously thought, see for example Attanasio, Hurst, and Pistaferri (2012), and Attanasio and Pistaferri (2014).

The evidence on the relation between the consumption distribution and the business cycle is more limited. A few papers have studied the dynamics of inequality during downturns. Consumption inequality tend to increase much less than earnings and income inequality during recessions, see Krueger, Perri, Pistaferri and Violante (2010). In particular Parker and Vissing-Jorgensen (2009) and Heathcote, Perri and Violante (2010b) show that the Great Recession has initially reduced inequality due to the pronounced reduction of consumption of the 10 th decile.

This paper provides a systematic empirical investigation aimed at shedding new light on the interactions between business cycles and the consumption distribution. We use CEX data to construct household level non-durable consumption (expenditures), using this measure we then calculate the mid-points of the different deciles of the consumption distribution for each quarter over the period 1984Q1-2010Q4. Our empirical analysis is carried out using a structural factor model (Bernanke, Boivin and Eliasz 2005, and Forni, Giannone, Lippi and Reichlin 2009). The model provides a unified framework to model a large amount of macroeconomic data together with the consumption deciles. Each series is modeled as the sum of two orthogonal components: the common and the idiosyncratic components. The former is driven by the macroeconomic shocks with 
pervasive effects on the economy, while the latter by series specific events unrelated to macro shocks (e.g. taste differences or measurement error in the consumption deciles). We characterize the cyclical dynamics of the common component of the consumption deciles and study the response of the consumption distribution to both a TFP and an economic policy uncertainty shock. Finally we check the validity of our econometric approach using simulated data.

The main findings are as follows. First, the common component of aggregate CEX consumption tracks aggregate consumption from the National Account (NIPA Tables) remarkably well at the business cycle frequencies. This is striking since the literature has extensively documented that the two aggregate series are substantially different in several respects. The reason why we obtain a close match between the two series is that our model can correct for a relatively general idiosyncratic component. Second, at the business cycle frequencies the top end of the distribution is much more volatile, suggesting a higher exposure of high-consumption individuals to economic fluctuations. The result suggests a higher cost of the business cycle for consumers in the right tail, about three times larger than for other consumers. Third, while the left tail of the distribution follows GDP with a lag of about two to three quarters, the right tail anticipates GDP by one to two quarters. The finding suggests that not only the exposure but also the decision rules are different across consumers, which gives rise to different consumption cycles. Fourth, TFP and economic policy uncertainty shocks have significantly higher effects on the top end of the distribution. Both shocks generate pro-cyclical movement in consumption inequality. Fifth, when using educational categories to split the consumption distribution rather than the deciles of consumption, we find that more educated individuals tend to respond to a larger extent and more quickly to the business cycle.

In trying to assess potential explanations that can account for the heterogeneity in behavior pointed out by these results, we find substantial heterogeneity across consumers in terms of expectations. More specifically, we find that highly educated individuals tend to forecast future economic conditions much better than other consumers. While expectations indeed play a role, we are not able to tell whether different consumers have different expectations or simply different information sets. Also, expectations are unlikely to explain the whole story. For instance, it is reasonable to think of the existence of rigidities and market imperfections, like liquidity constraints, which give rise to different decision rules.

The remainder of the paper is organized as follows: Section 2 introduces the econometric model. Section 3 describes the data used, and presents the results. Section 4 describes a set of simulations to assess the validity of the econometric approach. Section 5 discuss the identification of the TFP and the uncertainty shocks and presents the results. Section 6 provides a discussion of the results. Section 7 concludes. 


\section{The model}

In this section we describe our empirical model. The starting point is a model for individual consumption. Individual consumption is the sum of two orthogonal components, a common aggregate component and an idiosyncratic component. The common component is driven by common aggregate shocks while the idiosyncratic part includes shocks which do not have pervasive effects on the economy. Given that a panel is not available for individual consumption, we aggregate individual consumption data to construct the deciles of the consumption distribution and we derive the implied empirical model for the (mid-points of) consumption deciles.

Consumption $c_{j t}{ }^{1}$ of individual $j$, for $j=1, \ldots, n$, is given by

$$
c_{j t}=a_{j} f_{t}+\varepsilon_{j t}
$$

where $f_{t}$ is a $r \times 1$ vector of of macroeconomic factors, $a_{j}$ is the individual response to aggregate economic conditions and $\varepsilon_{j t}$ is a stationary idiosyncratic shock orthogonal to $f_{t}$ capturing all the determinants of individual consumption unrelated to aggregate conditions, e.g. health, luck or measurement error. Apart from stationarity we do not make any additional assumption about $\varepsilon_{j t}$.

We then aggregate individual consumption data into deciles and take the mid-point of each decile. The model for the $i$ th decile is then written as:

$$
c_{i t}=a_{i}^{c} f_{t}+\xi_{i t}^{c}
$$

where $c_{i t}=\frac{\sum_{j=1}^{n_{i}} c_{j t}}{n_{i}}, a_{i}^{c}=\frac{\sum_{j=1}^{n_{i}} a_{j}}{n_{i}} \xi_{i t}^{c}=\frac{\sum_{j=1}^{n_{i}} \varepsilon_{j t}}{n_{i}}$. Also the decile-specific consumption is driven by two orthogonal components: the common component $a_{i}^{c} f_{t}$ and the idiosyncratic component $\xi_{i t}$. Notice that $a_{i}^{c}$ is now the average response of consumption in group $i$ to macroeconomic factors. The latter includes unrestricted decile-specific shocks and measurement error which can accommodate differential measurement errors across deciles, since for example the measurement error is likely higher at the top of the distribution.

The dynamic relation between consumption units and macroeconomic shocks arises from the fact that the vector $f_{t}$ follows a VAR structure:

$$
N(L)^{-1} f_{t}=S u_{t}
$$

where $u_{t}$ is a $r$-dimensional vector of orthonormal white noise structural macroeconomic shocks, i.e. productivity shocks, policy shocks etc., and $N(L)$ a $r \times r$ matrix of polynomials in the lag operator $L$ with $N(0)=I$.

\footnotetext{
${ }^{1}$ Here there is a little abuse of notation. The index $j$ in the $c_{j t}$ should have an index $t$ in that the $j$ th consumer in two different periods are different individuals. However for sake of simplicity and to facilitate the exposition we abstract from this complication
} 
Using (2) and (3) we have

$$
c_{i t}=b_{i}^{c}(L) u_{t}+\xi_{i t}^{c}
$$

where $b_{i}^{c}(L)=a_{i}^{c} N(L) S$. The first term on the right-hand side of equation $(4), b_{i}^{c}(L) u_{t}$, describes the relation between consumption units and the macroeconomy. Macroeconomic shocks are dynamically transmitted to consumption through the impulse response functions $b_{i}^{c}(L)$.

In order to estimate the unobserved elements of $f_{t}$ we assume a factor structure for the whole economy. More specifically, every macroeconomic variable $x_{i t}$, for $i=1, \ldots, m$ is the sum of two mutually orthogonal components, the common component and the idiosyncratic component

$$
x_{i t}=a_{i}^{x} f_{t}+\xi_{i t}^{x}
$$

where the common component is again driven by common aggregate macroeconomic shocks

$$
a_{i}^{x} f_{t}=b_{i}^{x}(L) u_{t}
$$

where $b_{i}^{x}(L)=a_{i}^{x} N(L) S$. The idiosyncratic component, $\xi_{i t}^{x}$, in this case should be interpreted as measurement error for variables like GDP, or sectoral shocks in the case of sectoral variables. Following Bernanke, Boivin and Eliasz (2006), we allow for the possibility of having $s$ observed factors in $f_{t}$. Let $f_{t}^{o}$ be the vector of observed factors and $f_{t}^{u}$ of unobserved factors. The unobserved factors $\tilde{f}_{t}$ are estimated by means of the first $r-s$ principal components of the variables $x_{i t}$ in the dataset. The factor loading $a_{i}^{c}$ and $a_{i}^{x}$ are estimated by regressing $c_{i t}$ and $x_{i t}$ respectively onto $f_{t}$.

In Appendix A we list all the variables used for estimating the factors and their transformations. The deciles of consumptions are taken in $\operatorname{logs}$ for the sake of interpretation. ${ }^{2}$

\section{The dynamics of the consumption distribution}

\subsection{CEX data and summary statistics}

We construct household (non-durable) consumption from CEX data: 1984Q1 to 2010Q4. The CEX records consumption and expenditure for a large set of goods together with demographics and other households characteristics. Following a number of papers, see for example Attanasio and Weber (1995), Krueger and Perri (2006), Attanasio, Battistin, and Padula (2009), Parker and Vissing-Jorgensen (2009), we focus exclusively on household nondurable consumption expenditure per adult equivalent in real terms. ${ }^{3}$ In

\footnotetext{
${ }^{2}$ We have also used the deciles of the log distribution and the results are qualitatively the same. The results are not reported in the paper but are available upon request.

${ }^{3}$ We use an equivalence scale suggested by the World Bank, i.e. we divide our relevant variables by the squared root of the number of household members. We use the standard CPI to deflated the series.
} 
the construction of the non-durable consumption variable we strictly follow the definition used in Attanasio and Weber (1995). ${ }^{4}$ For each quarter we build the consumption distribution from the CEX microdata, applying the population weights provided therein. We then identify the different deciles and take the mid-points of each decile. ${ }^{5}$ We note that there are, on average, around 200 households within each decile/quarter cell.

Figure 1 shows some summary statistics of the deciles of the (log) consumption distribution. The top left panel plots the standard deviation of the raw data. It is clearly noticeable how the two tails of the distribution are more volatile than the central part of the distribution. In particular, the 10th decile is twice as volatile as the middle deciles. The top right panel displays the share of the variance of each decile attributable to the common component. For robustness, we plot these shares for 3 different specifications: using 6 (solid line), 10 (dashed line), and 16 (dotted line) Principal Components (PC). We note how "commonality" is substantially larger for central deciles. However, as shown in the bottom panels of Figure 1, for the raw data both the common (bottom left panel) and the idiosyncratic (bottom right panel) components are substantially more volatile at the top end of the distribution.

\subsection{NIPA and CEX at the business cycle frequencies}

We begin our analysis with a comparison between the NIPA and CEX aggregate nondurable consumption. Overtime the tracking between the CEX and the National Account statistics on aggregate consumption has been fading. A number of papers have described such occurrence and tried, with mixed results, to reconcile the two series or analyze the differences between the two measures of aggregate consumption (see for example Garner, 2006, Goldenberg and Ryan, 2009, Battistin and Padula, 2010, Aguiar and Bils, 2011, Attanasio and Pistaferri, 2014).

The upper panel of Figure 2 plots the cyclical component of the NIPA consumption (dotted line) and the cyclical component of the aggregate CEX (solid line). To compute the two series we apply a band-pass filter retaining only business cycle fluctuations (from 1.5 to 8 years). Fluctuations in the two series are substantially different, the correlation being around 0.5. Moreover the variance of the CEX aggregate is substantially larger

\footnotetext{
${ }^{4}$ In particular we refer to the following definition from Attanasio and Weber (1995): “...In what follows we consider various components of nondurable expenditure. In particular, for reasons to be discussed below, we look at food (defined as the sum of food at home, food away from home, alcohol, and tobacco) and expenditure on other nondurable goods and services, such as services, heating fuel, public and private transport (including gasoline), and personal care, and semidurables, defined as clothing and footwear..."

${ }^{5}$ Results are robust to assign each household to a given decile once and for all by ordering households mean consumption expenditure overtime. As a typical household is observed for 3 quarters, this in practice means that we average household consumption over that time period and we order that average to locate each household in the appropriate decile.
} 
than the NIPA counterpart.

The lower panel of Figure 2 plots the cyclical component of the NIPA consumption (dotted line) and the cyclical component of the common component of the aggregate CEX (solid line). The latter is obtained by applying the above filter to the common component of the CEX aggregate. ${ }^{6}$ The two series track each other remarkably well, with a correlation coefficient of around 0.8 . This shows that once the idiosyncratic component is removed from the data, the remaining common component displays fluctuations which are very similar to those observed in the NIPA aggregate.

A few remarks are in order. First, there is a non-negligible part of persistent fluctuations in the CEX which is idiosyncratic. This is one of the reason why it has been hard to reconcile the two series even at the business cycle frequencies. Second, the result is not a mechanic implication of the factor model. Although both series are driven by a common component, the correlation between the two series could in principle be zero given that the number of principal components is larger than one. Third, our claim is that only fluctuations at the business cycle frequencies in the two components are similar and not the two series in general. Importantly for our analysis, we note that any differences between the CEX and NIPA aggregate common components series are orthogonal to the business cycle, i.e. it is not true that CEX common component systematically over or underestimate NIPA common component in booms or downturns.

We believe that the finding presented in this section is extremely important. On the one hand it is the first piece of evidence documenting that the two series can track each others remarkably well. On the other hand it is an important validation of our modeling strategy and suggests that our approach can be successfully employed to investigate business cycle fluctuation using CEX consumption data.

\subsection{One, two, three consumption cycles}

Figure 3 plots the correlations at various leads and lags of the cyclical component of GDP with the cyclical component of the common component of the deciles, i.e. the band-pass filtered component of $a_{i t}^{c} f_{t}$. The $x$-axis refers to the lags and leads of the deciles. The correlations are remarkably high for all the deciles, with a minimum for the 1st decile of 0.77 and a maximum for the 10th decile of 0.87 . Conversely, the dynamic structure is very different across deciles. While the left tail of the distribution follows GDP with a lag of about two to three quarters, the right tail anticipates GDP by one to two quarters. ${ }^{7}$ A similar message emerges from Figure 4, where we plot the cyclical component of the GDP (dashed line) together with the cyclical component of the common component

\footnotetext{
${ }^{6}$ Nondurables CEX aggregate consumption is one of the series of the macroeconomic dataset so we can compute the common component.

${ }^{7}$ The same finding is confirmed either using the NIPA or CEX aggregate consumption.
} 
of the consumption deciles (solid line). The 10th decile leads while lower deciles lag the fluctuations in the GDP. These results suggest that there are actually three cycles which are similar in amplitude but differ by a phase shift. Fluctuations in GDP follow fluctuations in the 10th decile with a delay of two quarters and fluctuations in the left tail of the distribution follows GDP fluctuations with a lag of about three quarters.

Figure 5 reports the variance at cyclical frequencies of the common component of the consumption deciles rescaled by the variance of the aggregate CEX consumption. The volatility of the central deciles is similar in magnitude to that of CEX aggregate consumption while the 1st and 10th deciles are much more volatile, their variances being about two and three times larger than the aggregate consumption, respectively.

The findings discussed above point out two important facts. First, the exposure to cyclical fluctuations is different across deciles. It is much higher in the right tail and, to a substantially lesser extent, in the left tail than for mid-deciles. This has two implications in terms of the cost of cyclical fluctuations. First, the business cycle is more costly for the two tails, in particular the right one. Second, the cost of the business cycle measured solely with aggregate data can be substantially underestimated. Indeed we aggregate the volatilities of the different deciles using as weights the ratio of the consumption decile over total consumption (the sum of the deciles). We find that the cost is $40 \%$ higher than that obtained using only the volatility of aggregate consumption, the weighted sum of the decile variances is 1.64 while the variance of the CEX agregate is only $1.18 .^{8}$ The result is in line with the theoretical predictions in Mankiw and Zeldes (1991) where the consumption of the stockholders, i.e. the wealthy consumers, is much more volatile, and with the work of Krusell et al. (2009). However, it is in contrast with a large body of theoretical models where wealthy consumers tend to smooth consumption much more than poor consumers who behave in a hand-to-mouth fashion; notable exceptions are Parker and Vissing-Jorgensen (2009), and Parker (2014).

The second fact, implied by the correlation structure of the consumption deciles and GDP, is that average decision rules (within decile) are substantially different across deciles. The right tail moves first, pushing aggregate consumption and GDP, and then the rest of the distribution follows with a lag that is increasing as we look at the left part of the distribution. This latter fact will be discussed in detail in section 6 .

\section{Simulations}

We run a series of simulations in order to assess whether our econometric strategy is able to correctly estimate true heterogeneity in the common component which we model in the data generating process. In other words, we test whether our procedure is able to

\footnotetext{
${ }^{8}$ Following Lucas (1987) we measure the cost as $\lambda=\frac{1}{2} \sigma^{2} \theta$.
} 
correctly estimate the true decile effects, $a_{i}^{c}$. We generate individual-level consumption data from model (1) where the only common component is the growth rate of GDP. We construct the decile of the consumption distribution and then we regress the decile on the growth rate of GDP and get an estimate of $a_{i}^{c}$. Finally we compare the true value of $a_{i}^{c}$ used in the data generating process and its estimates. The simulation is done for different type of heterogeneity, i.e. values of $a_{i}$, and different idiosyncratic processes.

The simulation works as follows:

1. We generate $n=2000$ (corresponding to the average number of consumers in the survey per time period) different individual consumption paths of $T=108$ observations (corresponding to the time length of our data) from the equation

$$
c_{j t}=\alpha_{j}+a_{j} \Delta \log \left(G D P_{t}\right)+\xi_{j t} \quad \xi_{j t} \sim N\left(0, \sigma_{j t}^{2}\right) .
$$

where $\Delta \log \left(G D P_{t}\right)$ is the common component and $\xi_{j t}$ is the idiosyncratic component. Notice that the idiosyncratic component is very general, since its variance can differ both across individuals and across time.

2. We compute the deciles of the consumption distribution, we regress each decile on $\Delta \log \left(G D P_{t}\right)$ and estimate the mean response $a_{i}^{c}$.

We parametrize the model as follows. The constant term is $\alpha_{j}=1+\frac{j}{n / 10}$. The constant ranks consumers according to their expected conditional level of consumption. Individual 1 is the one with the lowest level of consumption, while individual 2000 is the one with the highest one. The variance of the idiosyncratic component, $\xi_{j t}$, is random and has a Gamma distribution $\sigma_{j t}^{2} \sim \operatorname{Gamma}(6, \beta)$ with scale parameter equal to 6 and shape parameter $\beta{ }^{9}$ We run the simulation for $\beta=1,2, \sqrt{10}$. Basically to generate $c_{j t}$, $t=1, \ldots, T$ we draw $T$ realizations of $\sigma_{j t}$ and $T$ realizations of $\xi_{j t}$.

Simulation \#1. We assume that high-consumption individuals have a larger response to GDP growth and set $a_{j}=\frac{j}{n}$. Top panel of Figure 6 reports the true mean values $a_{i}^{c}$ (solid line), and the estimated values in the three simulations $\hat{a}_{i}^{c}$, (dashed $\beta=1$, dotted $\beta=4$, dashed-dotted dotted $\beta=10$ ). When $\beta=1$ the parameters are estimated remarkably well. The distortion increases with the size of $\beta$. Two remarks are in order. For $\beta=1$ the mean of the variance of $\xi_{j t}$ is already 6 , about 15 times larger than the variance of $\Delta \log \left(G D P_{t}\right)$ which is 0.36 . For $\beta=2, \sqrt{10}$ the variance of the idiosyncratic component is unreasonably large. In the sensible case $\beta=1$ the model does very well. Second, the distortion drives to overestimating the response of the left tail and underestimating the response of the right tail. In other words, for extremely large values

\footnotetext{
${ }^{9}$ We consider a Gamma distribution since has positive support and the scale and the shape parameters allow us to play wit the mean and the variance of the distribution.
} 
of $\beta$ our procedure would underestimate the degree of heterogeneity of the consumption deciles.

In our simulation, individual consumers at the top of the distribution are more exposed to GDP growth then other consumers, meaning that the common component is more important at the top. However, when the idiosyncratic component is very large the deciles analysis tells a different story. The bottom panel of Figure 7 plots the percentage of variance of the deciles attributable to the common component for $\beta=1$ (dashed line), $\beta=2$ (dotted line) and $\beta=\sqrt{10}$ (dashed-dotted line). For $\beta=2$ and $\beta=\sqrt{10}$, the percentage of variance of the 10th decile accounted for by the common component is lower than that of the middle deciles. Therefore, one could falsely conclude that top consumers are more idiosyncratic, which is at odds with the true prediction. There are two implications: first, it is not advisable to interpret the percentage of common variance of the distribution deciles as the common variance of the individuals within the decile; second, although the individual-level idiosyncratic component is on average equal for all the consumers, the idiosyncratic shock for the decile can be substantially different across deciles.

Simulation \#2. We assume all the individuals have the same response to GDP growth and set $a_{j}=a=1$ for $j=1, \ldots, n$. Results are reported in the mid panel of Figure 6 . In this case our procedure would correctly capture a constant coefficient across deciles. ${ }^{10}$

Simulation \#3. We assume that low-consumption individuals have a larger response to GDP growth and set $a_{j}=1-\frac{j-1}{n}$. Results are reported in the bottom panel of Figure 6. Results are similar to those reported in Simulation 1 . When $\beta=1$ the parameters are estimated relatively well and the distortion increases with the size of $\beta$.

\section{Shocks}

So far the analysis has focused on the unconditional dynamics of the consumption deciles. Here we turn our attention on how the consumption distribution responds to economic shocks. We focus on two different shocks: a standard TFP shock and an economic policy uncertainty shock. We focus our attention to these two shocks since in the literature, they have been considered serious candidates to explain cyclical fluctuations (see Kidland and Prescott, 1982, among many others for TFP shocks and Bloom, 2009, and Baker, Bloom, and Davis, 2012).

\footnotetext{
${ }^{10}$ We also tried with a random coefficient uniformly distributed in $[0,1]$ and the for all the deciles the estimates are around 0.5.
} 


\subsection{TFP shock}

Identification proceeds as follows. First, we assume that total factor productivity (TFP) is the only observable factor and is ordered first in $f_{t}$. We estimate the VAR for the factors and we identify the shock as an innovation in the VAR equation for the TFP. ${ }^{11}$. More formally let $\Sigma$ be the variance covariance matrix of the innovation $\varepsilon_{t}=S u_{t}$ in the VAR equation $N(L)^{-1} f_{t}=S u_{t}$. Let $S$ be the Cholesky factor of $\Sigma$. The shock is the first shock of the vector $u_{t}=S^{-1} \varepsilon_{t}$. The first element of $a_{i}^{c} N(L) S$ and $a_{i}^{x} N(L) S$ are the impulse response functions of $c_{i t}$ and $x_{i t}$ respectively. An estimated of $N(L)^{-1}$ is obtained by inverting the matrix of estimated VAR coefficients obtained with OLS. An estimate of $S$ is obtained as the Cholesky factor of the estimated covariance matrix of the VAR residuals. This provides an estimate for $N(L)^{-1} S$.

Figure 7 plots the impulse response functions of main macroeconomic aggregates to a positive TFP shock. The solid line is the point estimate, the grey area represents the $68 \%$ confidence bands. The shock has the typical business cycles effects. It generates a protracted and significant increase in GDP, consumption, and investment, and a persistent reduction of the unemployment rate while and the federal funds rate barely moves. Notice that the responses of CEX and NIPA non-durables consumption are quite similar.

Figure 8 reports the effects of the shock on the consumption deciles ( $x$-axis). The upper left panel reports the average effect over the first year after the shock. The upper right panel reports the effects over the second year. The lower left panel reports the average effects over the third year after the shock. The lower right panel reports the average effect over the first 3 years. During the first year after the shock (upperleft panel), consumption increases only at the very top of the distribution, only the 10th decile responds positively and significantly. The response of the left part of the distribution is virtually zero. In the second year (upper-right panel), the left tail of the distribution catches up, the effects on the first two deciles being significantly different from zero. In the third year (lower-left panel) the effects are zero.

The top panel of Figure 9 plots the response of inequality, measured as the difference between the responses of the 10th decile and the 1st decile. Inequality increases significantly during the first two periods. The bottom panel of Figure 9 plots the variance of each decile attributable to the TFP shock rescaled by the variance of the CEX aggregate attributable to the TFP shock. The measure, as before, provides some evidence for the heterogeneity of the cost of cyclical fluctuations across deciles. The finding suggests that the cost for the 10th decile is significantly larger than that obtained for aggregate consumption (rescaled variance is significantly larger than one).

The main takeaway here is that TFP shocks have substantially larger effects at the

\footnotetext{
${ }^{11}$ This is the way standard technology shock is identified in Barsky and Sims (2011).
} 
top of the consumption distribution.

\section{$5.2 \quad$ Economic policy uncertainty shock}

Identification of the economic policy uncertainty shock is implemented as before but replacing the TFP series with the economic policy uncertainty measure of Baker, Bloom, and Davis (2012). The shock is the innovation in the uncertainty equation, the first equation in the VAR for the factors.

Figure 10 plots the impulse response functions of main macroeconomic aggregates to a positive uncertainty shock (an increase in uncertainty). The shock has the typical business cycles effects: GDP, consumption, and investment increase, unemployment falls and the federal funds rate barely moves. Again the responses of CEX and NIPA nondurables consumption are quite similar.

Figure 11 reports the effects of the shock on the consumption deciles ( $x$-axis). As before, within the first year after the shock, consumption reduces significantly only at the top of the distribution, the effects on the other deciles being not significant. In the second and third year consumption at the top continues significantly below its pre-shock level but now also the other consumption deciles reduce. So while in the short run only the left tail responds to the shock, at longer horizons all the distribution shifts to the left. The result replicates what we have found above. The left tail moves first and then the remainder of the distribution follows with a lag.

The top panel of Figure 12 plots the response of inequality. Inequality falls by $1 \%$ on impact and by about $0.5 \%$ for the first two years. The confidence bands however are quite large and the effect is not significantly different from 0 at the $68 \%$ confidence level. The bottom panel of Figure 9 plots the variance of the deciles attributable to the uncertainty shock rescaled by the variance of the CEX aggregate attributable to the shock. As for the TFP shock analysis, the rescaled variance is significantly larger than one only for the 10th decile.

Ultimately, results for a policy uncertainty shock are similar to those for the TFP shock. The right tail reacts to either shock with greater magnitude and speed.

\subsection{Evidence using educational categories}

We provide additional evidence for the effects of TFP and uncertainty shocks on consumption using CEX data aggregated by educational categories, and in particular by the highest level of education reached by the household head. We aggregate the data by four educational categories: less than high school; high school; some college; college and beyond education. This has the advantage of constructing a consumption series based on a permanent characteristic, i.e. education. 
In Table 1, we show the composition of the different consumption deciles in terms of education. As one would expect the bottom decile is made up mostly of lower education household heads. For example, up to the third decile at least $60 \%$ of individuals have at most a high school education. At the same time, the top 4 deciles are composed of individuals with at least some college education. It is quite interesting that in the bottom decile we still find that the college educated make up about $7 \%$ of the decile, and that in the top decile about $5 \%$ of the individuals have below high-school education. In this analysis, we employ the factor model developed in the previous sections, but we replace the dependent variable substituting the consumption deciles with the average household consumption by education category. We then apply the same identification strategy used in the previous two sections for the two shocks. Figure 13 plots the impulse response functions of the four education categories (rows) to the TFP shock (left column) and the uncertainty shock (right column). The response of highly educated individuals' consumption is much larger and more instantaneous than that of the other categories. This essentially confirms the previous analysis based on the classification of consumption by decile.

\section{Discussion}

Our findings robustly point out that the right tail of the consumption distribution and the consumption of the more educated individuals respond more and more quickly to shocks that drive cyclical fluctuations. The natural question arising from our finding is: what explains this heterogeneity? We believe there could be a number of explanations for this behavior, and here we focus on two, non-mutually exclusive, explanations. The first explanation is that consumers at the top of the distribution, those in the 9 th and 10 th decile, form expectations in a very different way from the rest of the individuals. In particular they seem to be much more forward looking and sensitive to future expected economic conditions (Armantier et al., 2014). To investigate such a possibility we use data from Michigan Survey of Consumers. We restrict our attention to two expectation variables: (i) the expected consumer sentiment index (ICE); and (ii) the expected business conditions over the next 12 months (BUS12). ${ }^{12}$

We use data for the two variables aggregated by educational categories. For each variable we have 5 series corresponding to the following educational categories: less than high school, high school, some college, college and graduate studies. We also consider as an alternative, and for robustness, the aggregation by income quartiles. We forecast one-quarter ahead the year on year growth rate of GDP with each variable. The forecast of the GDP growth from $t$ to $t+1$, say $\Delta G D P_{t+1 \mid t}$ is simply the value at time $t$ of

\footnotetext{
${ }^{12}$ See Appendix for the precise definitions of the two variables.
} 
ICE and BUS12. We compute forecast errors as $\Delta G D P_{t+1}-\Delta G D P_{t+1 \mid t}$ and we run the Diebold and Mariano test for any pair of forecast. For instance we compare the forecast made using ICE for the high school category with the forecast made with ICE for the college categories. The null hypothesis is that the two forecasts produce the same forecasting accuracy.

Table 2a displays the Diebold and Mariano statistics along with the p-values of the test. First, the results for the two variables, BUS12 and ICE are remarkably similar. Second, the forecast accuracy increases with the level of education, all the statistics except college versus graduate studies are positive. Third, the forecasts of the first category are significantly less accurate than all the other categories. Fourth, also high school graduates do predict worse than higher categories, although the difference in the forecasts are not significant.

Table $2 \mathrm{~b}$ displays the results for income categories. Forecast accuracy of the bottom $25 \%$ is significantly lower than that of the other quartiles. The second quartile also predicts worse than the third and the top quartile. The ICE and the DM statistics of the second versus the fourth is significant at the $10 \%$ level. Concluding, highly educated (wealthier) individuals are better at predicting their own consumption and the business cycle.

The findings suggest that there are significant differences in the accuracy of the forecast of future growth rates of GDP across individuals. This can explain, to some extent, the differences in the reaction of consumption across deciles. However what remains an intriguing open question is whether the differences also depend on different classes of expectations, general heterogeneity, or simply different information sets.

Expectations, however, are likely to be only part of the story. A second plausible explanation is that there are rigidities and market imperfections, such as liquidity constraints, which prevent consumer in the left and center of the distribution from promptly reacting to the new information about future economic conditions. Establishing the relative importance of the two explanations is undoubtedly interesting but beyond the scope of this paper.

\section{Conclusions}

In this paper we analyze the behavior of consumption across the business cycle for the past 30 years, allowing for heterogenous behavior of consumers across two dimensions: i. consumption deciles, and ii. education.

A number of important facts emerge from our analysis: first, we are able to capture quite well the aggregate business cycle behavior of the NIPA aggregate consumption using consumption measured from CEX microdata. This result is crucial for our analysis, 
but more importantly because allows policy analysis on business cycle consumption at the individual level or at a minimum at some more disaggreagated level then the NIPA aggregate level, which is somewhat limited for policy purposes. Second, we show how the business cycle common component of fluctuations is quite heterogenous across consumers and as such we show that welfare losses from business cycle fluctuations are actually nontrivial when one looks at the more detailed picture. Third, we show that the cyclical responses to the business cycles follow a very different dynamic for the bottom and top consumers. While top consumers move ahead of the cycle and respond more strongly, bottom consumers move with two to three quarters lag and have a much milder responses. Fourth, TFP as well as economic uncertainty shocks have much larger effects on top consumers. Fifth, one explanation we can give is that top (highly educated) consumers are much better at forecasting economic conditions and as such respond promptly to changing circumstances. From a policy perspective our analysis is crucial as it shows how aggregate shocks have very different impacts on different consumers. Ultimately, it is the role of policy to decide whether and with whom to intervene, without the type of analysis implemented in this paper that would essentially be an unfounded call. 


\section{References}

[1] Aguiar, Mark and Mark Bils, (2011). "Has Consumption Inequality Mirrored Income Inequality?" NBER Working Paper 16807.

[2] Armantier, O., Bruine de Bruin, W., Topa, G. and, van der Klaauw, W., (2014), "Inflation Expectations and Behavior: Do Survey Respondents Act on their Beliefs?", forthcoming, the International Economic Review.

[3] Attanasio, Orazio, James Bank, and Sarah Tanner (2002). "Asset holding and consumption volatility" Journal of Political Economy, 110 (4), 771792.

[4] Attanasio, Orazio, Erich Battistin, and Vincenzo Padula, (2009). "Inequality in Living Standards since 1980: Evidence from Expenditure Data" Mimeo.

[5] Attanasio, Orazio, Erik Hurst, and Luigi Pistaferri, (2012), "The evolution of income, consumption, and leisure inequality in the US, 1980-2010," NBER Working Papers: 17982 .

[6] Attanasio, Orazio, and Luigi Pistaferri, (2014), "Consumption inequality over the last half century. Evidence using the new PSID consumption measure", American Economic Review P\&P, 104(5): 112-126.

[7] Attanasio, Orazio and Guglielmo Weber, (1995). "Is Consumption Growth Consistent with Intertemporal Optimization? Evidence from the Consumer Expenditure Survey" Journal of Political Economy, 103(6):11211157.

[8] Baker, Scott, Nicholas Bloom, and Steve Davis (2012). "Measuring economic policy uncertainty". Stanford University mimeo.

[9] Barsky, Robert B. and Eric, R. Sims (2011). "News shocks and business cycles," Journal of Monetary Economics 58(3):273-289.

[10] Battistin, Erich and Mario Padula (2010). "Survey Instruments and the Reports of Consumer Expenditures: Evidence from the Consumer Expenditure Surveys" Mimeo, IFS.

[11] Bernanke Ben, Jean Boivin and Piotr Eliasz, (2005). "Measuring Monetary Policy: A Factor Augmented Autoregressive (FAVAR) Approach" The Quarterly Journal of Economics, 120:387422.

[12] Bloom, Nick, (2009). "The Impact of Uncertainty Shocks" Econometrica, $77(3): 623685$. 
[13] Forni Mario, Domenico Giannone, Marco Lippi, and Lucrezia Reichlin, (2009). "Opening the Black Box: Structural Factor Models with Large Cross-Sections" Econometric Theory, 25:13191347.

[14] Goldenberg, Karen and Jay Ryan,(2009). "Evolution and Change in the Consumer Expenditure Surveys: Adapting Methodologies to Meet Changing Needs, BLS.

[15] Guvenen, Fatih, (2011). "Macroeconomics with Heterogeneity: A Practical Guide" Economic Quarterly, 97:255326.

[16] Heathcote, Jonathan, Fabrizio Perri, and Giovanni L. Violante (2010a). "Unequal We Stand: An Empirical Analysis if Economic Inequality in the US, 19672006" Review of Economic Dynamics 13(1): 1551.

[17] Heathcote, Jonathan, Fabrizio Perri, and Giovanni L. Violante (2010b). "Inequality in Times of Crisis: Lessons from the Past and a First Look at the Current Recession' VoxEU.org, February 2.

[18] Heathcote, Jonathan, Kjetil Storesletten, and Giovanni L. Violante, (2009). "Quantitative Macroeconomics with Heterogeneous Households" Annual Review of Economics, 1:319354.

[19] Kydland, Finn E and Edward C. Prescott, (1982). "Time to Build and Aggregate Fluctuations" Econometrica 50(6):1345-1370.

[20] Krueger, Dirk and Fabrizio Perri, (2006). "Does income inequality lead to consumption inequality? Evidence and theory" Review of Economic Studies, 73(1):163193.

[21] Krueger, Dirk, Fabrizio Perri, Luigi Pistaferri, and Giovanni L. Violante. (2010). "Cross-Sectional Facts for Macroeconomists" Review of Economic Dynamics 13(1): 114.

[22] Krusell, Per and Anthony Smith, (1999). "On the Welfare Effects of Eliminating Business Cycles" Review of Economic Dynamics, 2(1):245272.

[23] Krusell, Per, Toshihiko Mukoyama, Aysegul Sahin and Anthony A. Smith, Jr., (2009). "Revisiting the Welfare Effects of Eliminating Business Cycles," Review of Economic Dynamics, Elsevier for the Society for Economic Dynamics, vol. $12(3): 393-402$.

[24] Lucas, Robert, (1987). "Models of Business Cycles".

[25] Mankiw, Gregory and Stephen P. Zeldes, (1991). "The consumption of stockholders and nonstockholders" Journal of Financial Economics, 29:97112. 
[26] Parker, Jonathan A. and Annette Vissing-Jorgensen, "Who Bears the Aggregate Fluctuations and How?," working paper Northwestern University, 2009.

[27] Parker, Jonathan A., "Why Don't Households Smooth Consumption? Evidence from a 25 million dollar experiment," mimeo MIT, 2014.

[28] Primiceri, Giorgio and Thijs van Rens (2005). "Heterogeneous Life-Cycle Profiles, Income Risk and Consumption Inequality", Journal of Monetary Economics, 56(1):20-39.

[29] Stock, James H. and Mark W. Watson, Implications of Dynamic Factor Models for VAR Analysis, NBER Working Papers no. 11467, 2005. 


\section{Appendix A}

Transformations: $1=$ levels, $2=$ first differences of the original series, $5=$ first differences of logs of the original series.

\begin{tabular}{|c|c|c|c|}
\hline no.series & Transf. & Mnemonic & Long Label \\
\hline 1 & 5 & GDPC1 & Real Gross Domestic Product, 1 Decimal \\
\hline 2 & 5 & GNPC96 & Real Gross National Product \\
\hline 3 & 5 & NICUR/GDPDEF & National Income/GDPDEF \\
\hline 4 & 5 & DPIC96 & Real Disposable Personal Income \\
\hline 5 & 5 & OUTNFB & Nonfarm Business Sector: Output \\
\hline 6 & 5 & FINSLC1 & Real Final Sales of Domestic Product, 1 Decimal \\
\hline 7 & 5 & FPIC1 & Real Private Fixed Investment, 1 Decimal \\
\hline 8 & 5 & PRFIC1 & Real Private Residential Fixed Investment, 1 Decimal \\
\hline 9 & 5 & PNFIC1 & Real Private Nonresidential Fixed Investment, 1 Decimal \\
\hline 10 & 5 & GPDIC1 & Real Gross Private Domestic Investment, 1 Decimal \\
\hline 11 & 5 & PCECC96 & Real Personal Consumption Expenditures \\
\hline 12 & 5 & PCNDGC96 & Real Personal Consumption Expenditures: Nondurable Goods \\
\hline 13 & 5 & PCDGCC96 & Real Personal Consumption Expenditures: Durable Goods \\
\hline 14 & 5 & PCESVC96 & Real Personal Consumption Expenditures: Services \\
\hline 15 & 5 & GPSAVE/GDPDEF & Gross Private Saving/GDP Deflator \\
\hline 16 & 5 & FGCEC1 & Real Federal Consumption Expenditures \& Gross Investment, 1 Decimal \\
\hline 17 & 5 & FGEXPND/GDPDEF & Federal Government: Current Expenditures/ GDP deflator \\
\hline 18 & 5 & FGRECPT/GDPDEF & Federal Government Current Receipts/ GDP deflator \\
\hline 19 & 2 & FGDEF & Federal Real Expend-Real Receipts \\
\hline 20 & 1 & CBIC1 & Real Change in Private Inventories, 1 Decimal \\
\hline 21 & 5 & EXPGSC1 & Real Exports of Goods \& Services, 1 Decimal \\
\hline 22 & 5 & IMPGSC1 & Real Imports of Goods \& Services, 1 Decimal \\
\hline 23 & 5 & $\mathrm{CP} / \mathrm{GDPDEF}$ & Corporate Profits After Tax/GDP deflator \\
\hline 24 & 5 & NFCPATAX/GDPDEF & Nonfinancial Corporate Business: Profits After Tax/GDP deflator \\
\hline 25 & 5 & $\mathrm{CNCF} / \mathrm{GDPDEF}$ & Corporate Net Cash Flow/GDP deflator \\
\hline 26 & 5 & DIVIDEND/GDPDEF & Net Corporate Dividends/GDP deflator \\
\hline 27 & 5 & HOANBS & Nonfarm Business Sector: Hours of All Persons \\
\hline 28 & 5 & OPHNFB & Nonfarm Business Sector: Output Per Hour of All Persons \\
\hline 29 & 5 & UNLPNBS & Nonfarm Business Sector: Unit Nonlabor Payments \\
\hline 30 & 5 & ULCNFB & Nonfarm Business Sector: Unit Labor Cost \\
\hline 31 & 5 & WASCUR/CPI & Compensation of Employees: Wages \& Salary Accruals/CPI \\
\hline 32 & 5 & COMPNFB & Nonfarm Business Sector: Compensation Per Hour \\
\hline 33 & 5 & COMPRNFB & Nonfarm Business Sector: Real Compensation Per Hour \\
\hline 34 & 5 & GDPCTPI & Gross Domestic Product: Chain-type Price Index \\
\hline 35 & 5 & GNPCTPI & Gross National Product: Chain-type Price Index \\
\hline 36 & 5 & GDPDEF & Gross Domestic Product: Implicit Price Deflator \\
\hline 37 & 5 & GNPDEF & Gross National Product: Implicit Price Deflator \\
\hline 38 & 5 & INDPRO & Industrial Production Index \\
\hline 39 & 5 & IPBUSEQ & Industrial Production: Business Equipment \\
\hline 40 & 5 & IPCONGD & Industrial Production: Consumer Goods \\
\hline 41 & 5 & IPDCONGD & Industrial Production: Durable Consumer Goods \\
\hline 42 & 5 & IPFINAL & Industrial Production: Final Products (Market Group) \\
\hline 43 & 5 & IPMAT & Industrial Production: Materials \\
\hline 44 & 5 & IPNCONGD & Industrial Production: Nondurable Consumer Goods \\
\hline 45 & 2 & AWHMAN & Average Weekly Hours: Manufacturing \\
\hline 46 & 2 & AWOTMAN & Average Weekly Hours: Overtime: Manufacturing \\
\hline
\end{tabular}




\begin{tabular}{|c|c|c|c|}
\hline no.series & Transf. & Mnemonic & Long Label \\
\hline 47 & 2 & CIVPART & Civilian Participation Rate \\
\hline 48 & 5 & CLF16OV & Civilian Labor Force \\
\hline 49 & 5 & CE16OV & Civilian Employment \\
\hline 50 & 5 & USPRIV & All Employees: Total Private Industries \\
\hline 51 & 5 & USGOOD & All Employees: Goods-Producing Industries \\
\hline 52 & 5 & SRVPRD & All Employees: Service-Providing Industries \\
\hline 53 & 5 & UNEMPLOY & Unemployed \\
\hline 54 & 5 & UEMPMEAN & Average (Mean) Duration of Unemployment \\
\hline 55 & 2 & UNRATE & Civilian Unemployment Rate \\
\hline 56 & 5 & HOUST & Housing Starts: Total: New Privately Owned Housing Units Started \\
\hline 57 & 2 & FEDFUNDS & Effective Federal Funds Rate \\
\hline 58 & 2 & TB3MS & 3-Month Treasury Bill: Secondary Market Rate \\
\hline 59 & 2 & GS1 & 1-Year Treasury Constant Maturity Rate \\
\hline 60 & 2 & GS10 & 10-Year Treasury Constant Maturity Rate \\
\hline 61 & 2 & AAA & Moody's Seasoned Aaa Corporate Bond Yield \\
\hline 62 & 2 & BAA & Moody's Seasoned Baa Corporate Bond Yield \\
\hline 63 & 2 & MPRIME & Bank Prime Loan Rate \\
\hline 64 & 5 & BOGNONBR & Non-Borrowed Reserves of Depository Institutions \\
\hline 65 & 5 & TRARR & Board of Governors Total Reserves, Adjusted for Changes in Reserve \\
\hline 66 & 5 & BOGAMBSL & Board of Governors Monetary Base, Adjusted for Changes in Reserve \\
\hline 67 & 5 & M1SL & M1 Money Stock \\
\hline 68 & 5 & M2MSL & M2 Minus \\
\hline 69 & 5 & M2SL & M2 Money Stock \\
\hline 70 & 5 & BUSLOANS & Commercial and Industrial Loans at All Commercial Banks \\
\hline 71 & 5 & CONSUMER & Consumer (Individual) Loans at All Commercial Banks \\
\hline 72 & 5 & LOANINV & Total Loans and Investments at All Commercial Banks \\
\hline 73 & 5 & REALLN & Real Estate Loans at All Commercial Banks \\
\hline 74 & 5 & TOTALSL & Total Consumer Credit Outstanding \\
\hline 75 & 5 & CPIAUCSL & Consumer Price Index For All Urban Consumers: All Items \\
\hline 76 & 5 & CPIULFSL & Consumer Price Index for All Urban Consumers: All Items Less Food \\
\hline 77 & 5 & CPILEGSL & Consumer Price Index for All Urban Consumers: All Items Less Energy \\
\hline 78 & 5 & CPILFESL & Consumer Price Index for All Urban Consumers: All Items Less Food \& Energy \\
\hline 79 & 5 & CPIENGSL & Consumer Price Index for All Urban Consumers: Energy \\
\hline 80 & 5 & CPIUFDSL & Consumer Price Index for All Urban Consumers: Food \\
\hline 81 & 5 & PPICPE & Producer Price Index Finished Goods: Capital Equipment \\
\hline 82 & 5 & PPICRM & Producer Price Index: Crude Materials for Further Processing \\
\hline 83 & 5 & PPIFCG & Producer Price Index: Finished Consumer Goods \\
\hline 84 & 5 & PPIFGS & Producer Price Index: Finished Goods \\
\hline 85 & 5 & OILPRICE & Spot Oil Price: West Texas Intermediate \\
\hline 86 & 5 & USSHRPRCF & US Dow Jones Industrials Share Price Index (EP) NADJ \\
\hline 87 & 5 & US500STK & US Standard \& poor's Index if 500 Common Stocks \\
\hline 88 & 5 & USI62...F & US Share Price Index NADJ \\
\hline 89 & 5 & USNOIDN.D & US Manufacturers New Orders for Non Defense Capital Goods (BCI 27) \\
\hline 90 & 5 & USCNORCGD & US New Orders of Consumer Goods \& Materials (BCI 8) CONA \\
\hline 91 & 1 & USNAPMNO & US ISM Manufacturers Survey: New Orders Index SADJ \\
\hline 92 & 5 & USVACTOTO & US Index of Help Wanted Advertising VOLA \\
\hline 93 & 5 & USCYLEAD & US The Conference Board Leading Economic Indicators Index SADJ \\
\hline 94 & 5 & USECRIWLH & US Economic Cycle Research Institute Weekly Leading Index \\
\hline 95 & 2 & GS10-FEDFUNDS & \\
\hline 96 & 2 & GS1-FEDFUNDS & \\
\hline 97 & 2 & BAA-FEDFUNDS & \\
\hline
\end{tabular}




\begin{tabular}{ccll}
\hline \hline no.series & Transf. & Mnemonic & Long Label \\
\hline 98 & 5 & GEXPND/GDPDEF & Government Current Expenditures/ GDP deflator \\
99 & 5 & GRECPT/GDPDEF & Government Current Receipts/ GDP deflator \\
100 & 2 & GDEF & Governnent Real Expend-Real Receipts \\
101 & 5 & GCEC1 & Real Government Cons. Expenditures \& Gross Investment, 1 Decimal \\
102 & 5 & & Real Federal Cons. Expenditures \& Gross Investment National Defense \\
103 & 2 & Federal primary deficit \\
104 & 5 & Real Federal Current Tax Revenues \\
105 & 5 & Real Government Current Tax Revenues \\
106 & 2 & Government primary deficit \\
107 & 5 & Real (/GDPDEF) Gov. Social Benefit \\
108 & 1 & & Gov. social benefits/ Gov. Curr Exp \\
\hline \hline
\end{tabular}




\section{Appendix B}

ICE is constructed as a weighted average of three variables BUS12, BUS5 and DUR. The three variables measure the percentage of responses reporting good future conditions minus the percentage of responses reporting bad future conditions the following questions:

BUS12: "Now turning to business conditions in the country as a whole-do you think that during the next twelve months we'll have good times financially, or bad times, or what"

BUS5: "Looking ahead, which would you say is more likely-that in the country as a whole we'll have continuous good times during the next five years or so, or that we will have periods of widespread unemployment or depression, or what"

DUR: "About the big things people buy for their homes-such as furniture, a refrigerator, stove, television, and things like that. Generally speaking, do you think now is a good or bad time for people to buy major household items?". 


\section{Tables}

\begin{tabular}{cccccc}
\hline \hline decile & $<$ HS & HS & Some col. & $>$ = College & Total \\
1 & 40.64 & 33.74 & 17.67 & 7.95 & 100.00 \\
2 & 27.96 & 38.45 & 20.61 & 12.98 & 100.00 \\
3 & 20.60 & 38.40 & 22.54 & 18.46 & 100.00 \\
4 & 15.67 & 38.62 & 23.33 & 22.37 & 100.00 \\
5 & 12.32 & 37.25 & 23.35 & 27.08 & 100.00 \\
6 & 10.12 & 34.93 & 23.58 & 31.37 & 100.00 \\
7 & 7.98 & 32.69 & 23.25 & 36.08 & 100.00 \\
8 & 6.63 & 30.28 & 22.26 & 40.83 & 100.00 \\
9 & 5.34 & 26.37 & 21.25 & 47.05 & 100.00 \\
10 & 5.57 & 25.50 & 20.85 & 48.08 & 100.00 \\
\hline \hline
\end{tabular}

Table 1: composition of the consumer deciles in terms of educational attainments. 


\begin{tabular}{|c|c|c|c|c|c|c|c|c|}
\hline & \multicolumn{4}{|c|}{ BUS12 } & \multicolumn{4}{|c|}{ ICE } \\
\hline & HS & Some col. & College & Graduate & $<\mathrm{HS}$ & Some col. & College & Graduate \\
\hline$<\mathrm{HS}$ & 2.45 & 2.31 & 2.56 & 2.72 & 2.56 & 2.34 & 2.83 & 2.77 \\
\hline ( $p$-value) & $(0.01)$ & $(0.01)$ & $(0.01)$ & $(0.00)$ & $(0.01)$ & $(0.01)$ & $(0.00)$ & $(0.00)$ \\
\hline HS & & 0.26 & 1.28 & 1.07 & & -0.20 & 1.42 & 0.86 \\
\hline ( $p$-value) & & $(0.40)$ & $(0.10)$ & $(0.14)$ & & $(0.58)$ & $(0.08)$ & $(0.19)$ \\
\hline Some col. & & & 1.28 & 0.82 & & & 2.05 & 1.12 \\
\hline ( $p$-value) & & & $(0.10)$ & $(0.21)$ & & & $(0.02)$ & $(0.13)$ \\
\hline College & & & & -0.21 & & & & -0.85 \\
\hline ( $p$-value) & & & & $(0.58)$ & & & & $(0.80)$ \\
\hline
\end{tabular}

Table 2a: Diebold and Mariano statistics for education categories. The forecast produced by each variable listed in the first column is tested against the forecast produced by the variables listed in the first row of the other columns. The null hypothesis is that the the forecasting accuracy is equal for the two forecast considered. $p$-values are displayed in parenthesis.

\begin{tabular}{cccccccc}
\hline \hline & \multicolumn{3}{c}{ BUS12 } & & \multicolumn{3}{c}{ ICE } \\
\cline { 2 - 3 } \cline { 6 - 7 } \cline { 5 - 7 } Bottom 25\% & Second 25\% & Third 25\% & Top 25\% & & Second 25\% & Third 25\% & Top 25\% \\
(p-value) & 2.65 & 1.96 & 2.39 & & 2.86 & 2.87 & 3.25 \\
Second 25\% & $(0.00)$ & $(0.03)$ & $(0.01)$ & & $(0.00)$ & $(0.00)$ & $(0.00)$ \\
(p-value) & & 0.10 & 1.07 & & & 0.88 & 1.58 \\
Third 25\% & & $(0.46)$ & $(0.14)$ & & & $(0.19)$ & $(0.06)$ \\
(p-value) & & & 1.50 & & & & 1.10 \\
\hline \hline
\end{tabular}

Table 2b: Diebold and Mariano statistics for income categories. The forecast produced by each variable listed in the first column is tested against the forecast produced by the variables listed in the first row of the other columns. The null hypothesis is that the the forecasting accuracy is equal for the two forecast considered. $p$-values are displayed in parenthesis. 


\section{Figures}
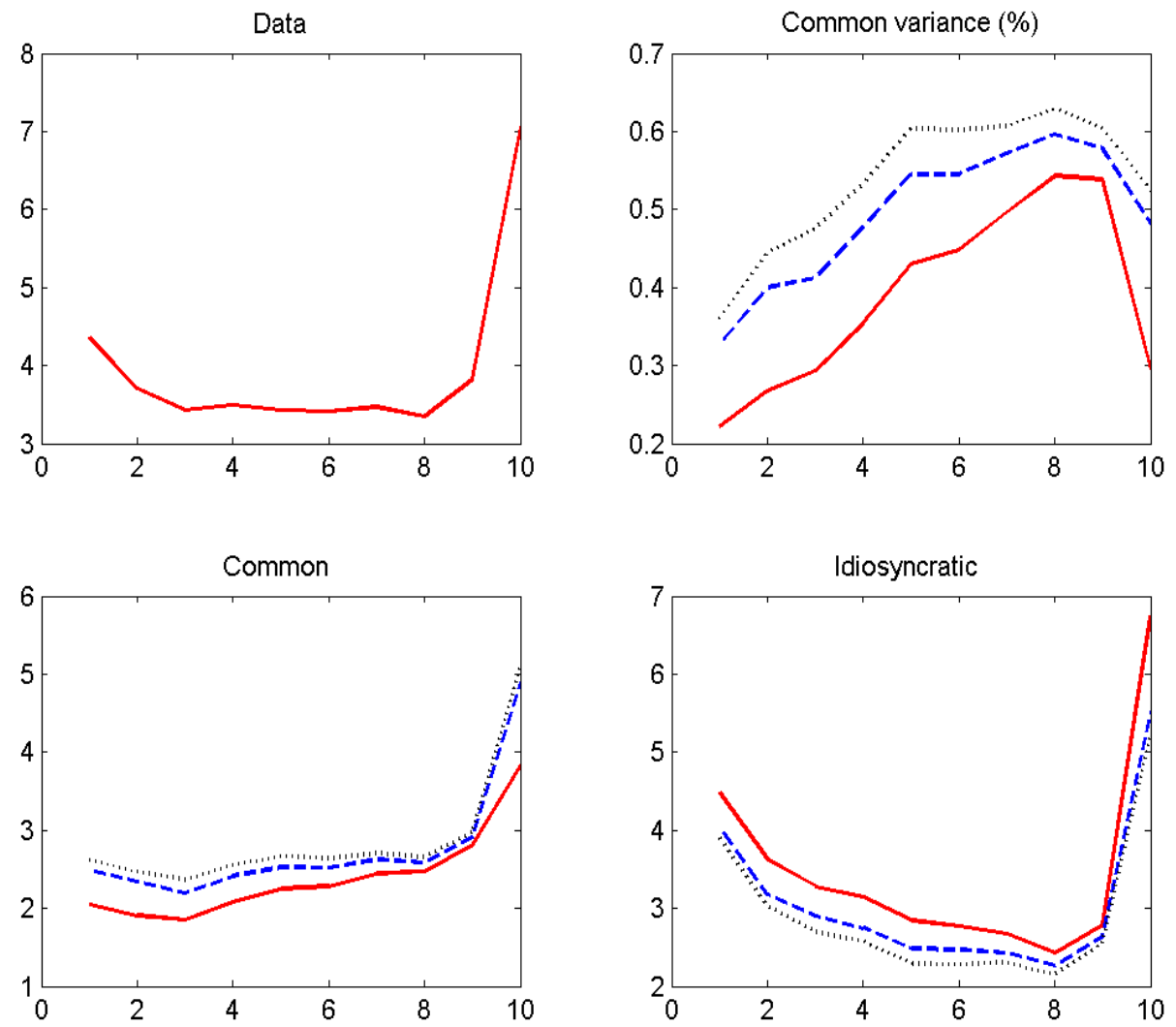

Figure 1:. Summary statistics of the deciles of the consumption distribution. Top left panel - standard deviation of raw data. The top right panel - percentage of variance of the deciles attributable to the common component. Bottom left panel - standard deviation of the common component. The bottom right panel - standard deviation of the idiosyncratic component. Solid line -6 principal components; the dashed line -10 principal components. Dotted line -16 principal components. 

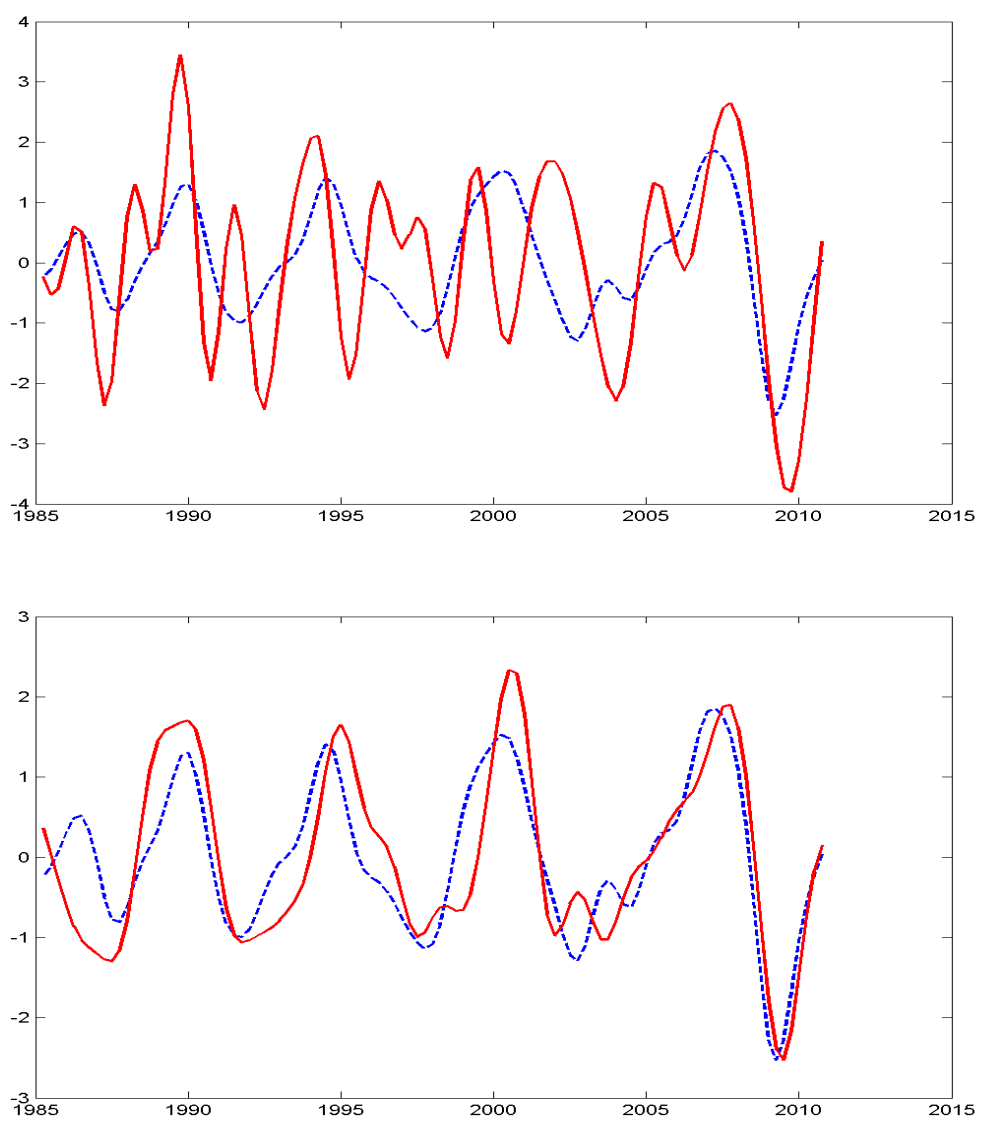

Figure 2. Upper panel - cyclical component of the NIPA consumption (dotted line) and cyclical component of the aggregate CEX (solid line). Lower panel: cyclical component of the NIPA consumption (dotted line) and cyclical component of the common component of the aggregate CEX (solid line). 

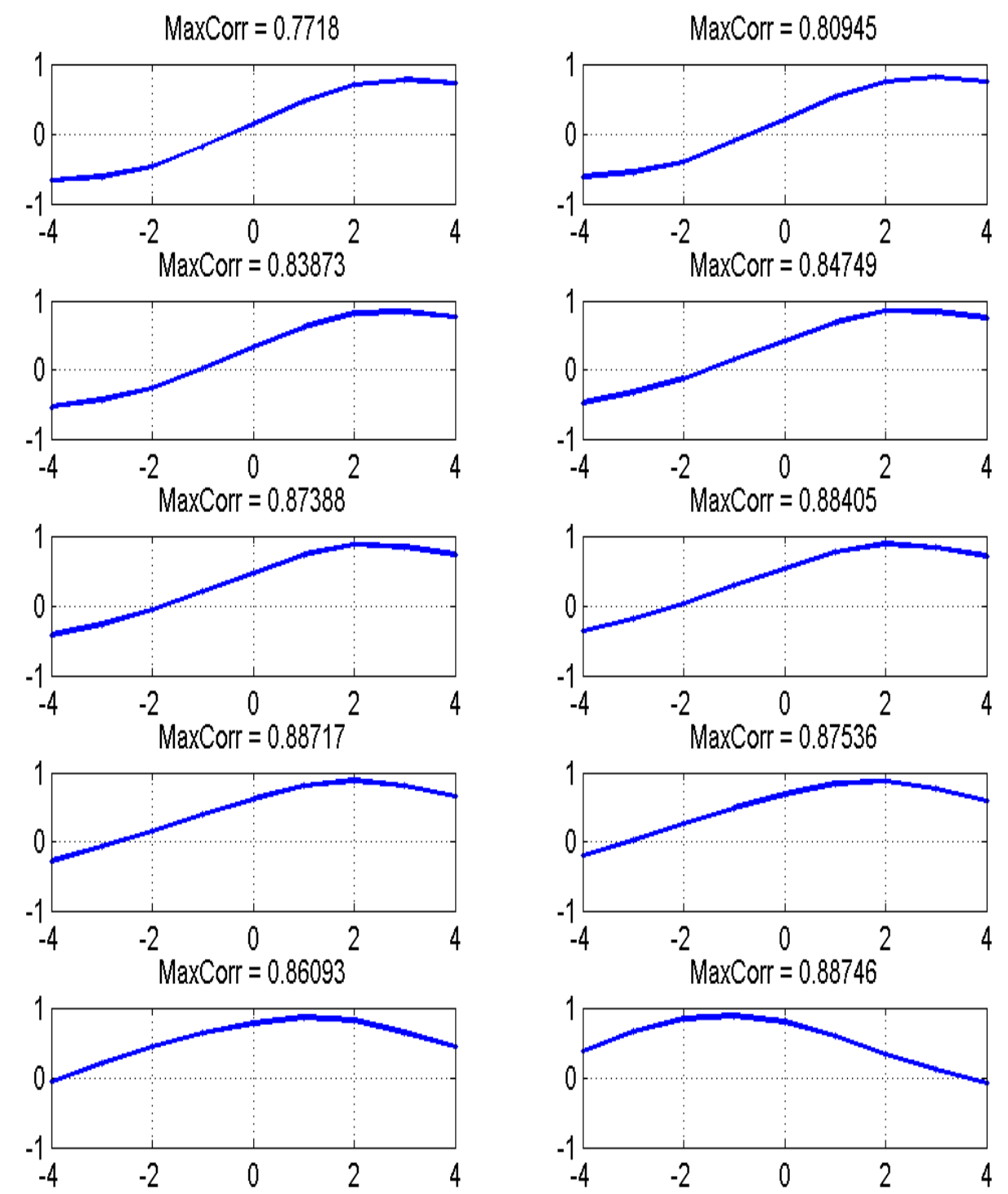

Figure 3. Correlations between lags and leads of the cyclical common components of the consumption deciles and the cyclical components of GDP. On the $x$-axis there are the lags (negative values) and the leads (positive values) of the consumption deciles. Each panel also displays the maximal correlation. 
Decile 1
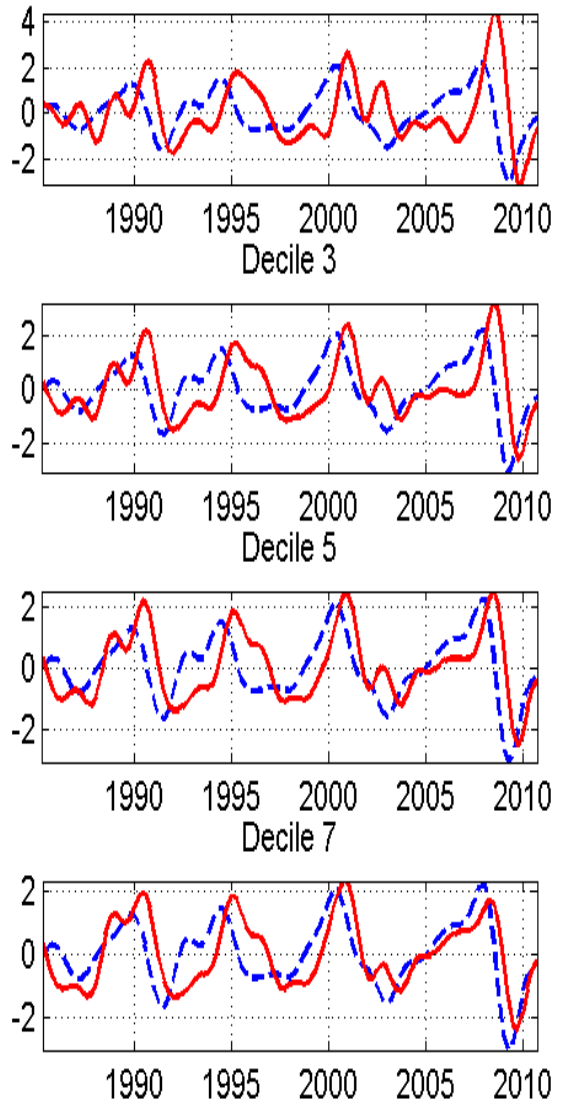
Decile 9

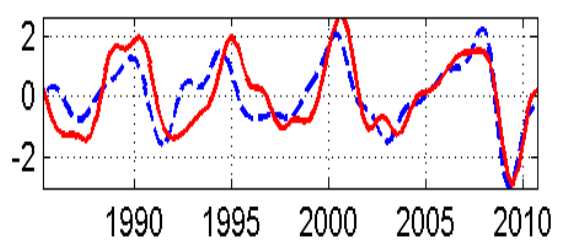

Decile 2

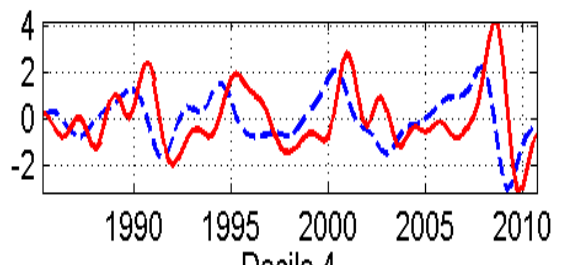
Decile 4
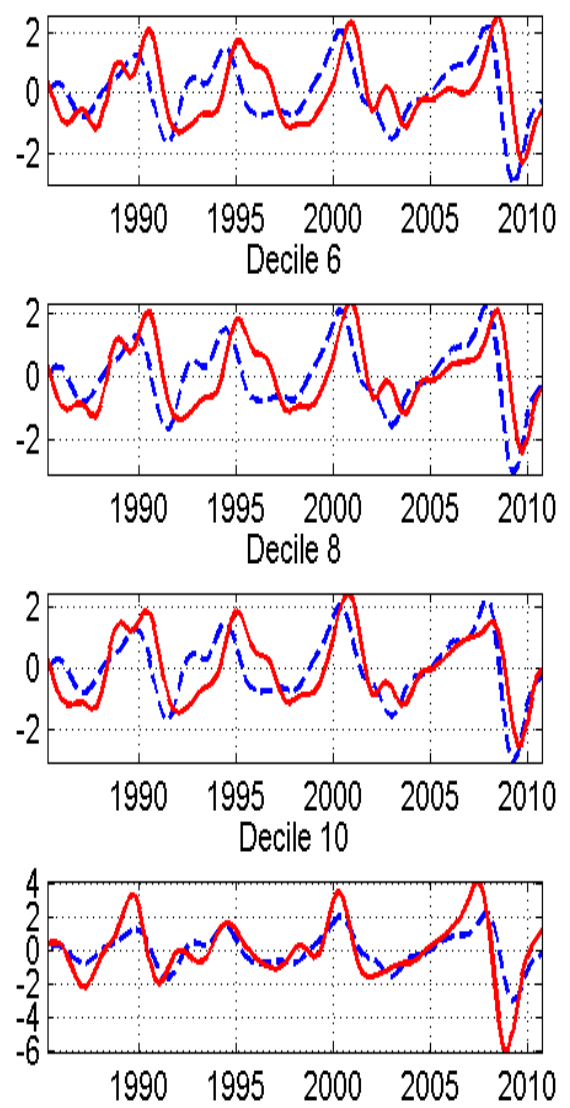

Figure 4. Cyclical component of the GDP (dashed line) and the cyclical component of the common component of the deciles (solid line). 


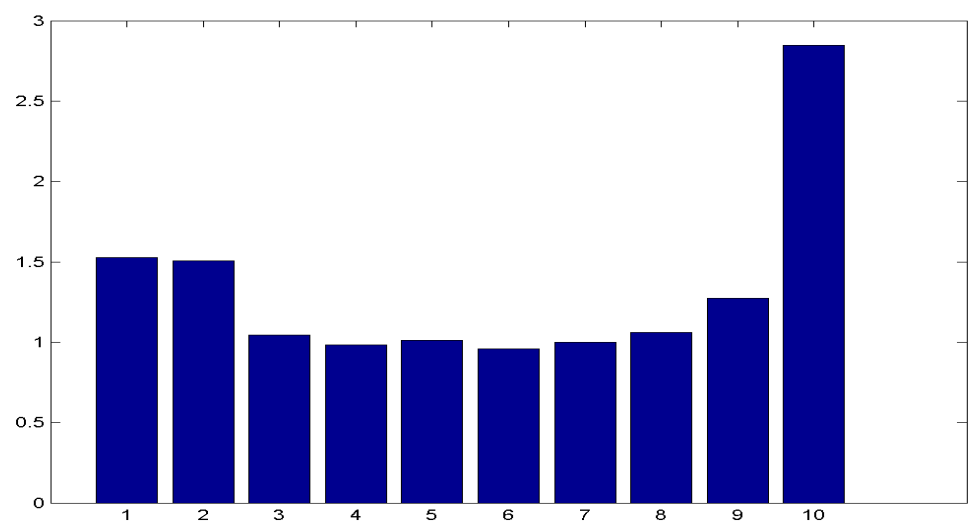

Figure 5. Variance at cyclical frequencies of the common component of the consumption deciles rescaled by the variance of the aggregate CEX consumption. 

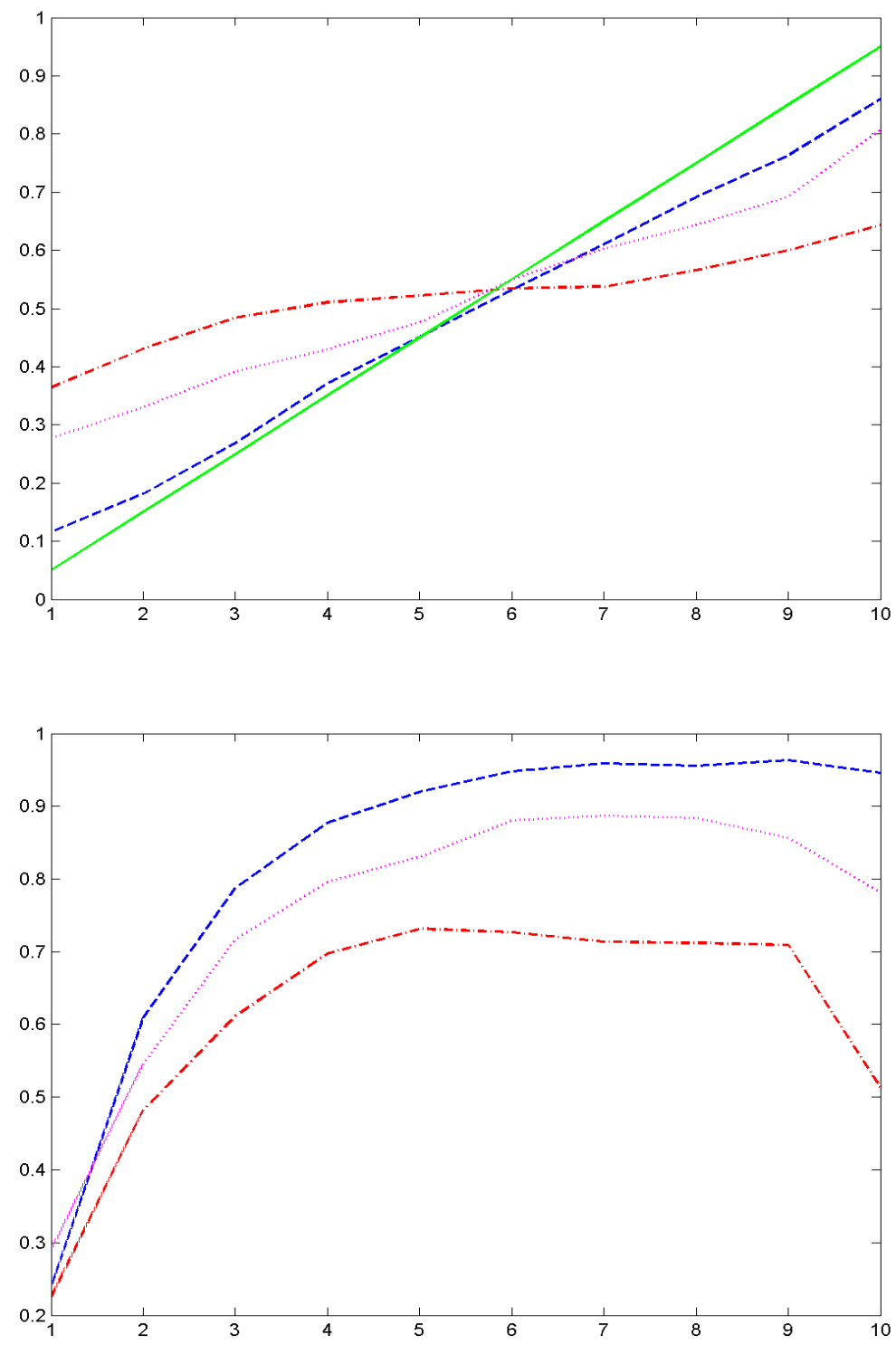

Figure 6. Top panel simulation \# 1. True mean values $a_{i}^{c}$ (solid line), and the estimated values $\hat{a}_{i}^{c}$, (dashed $\beta=1$, dotted $\beta=4$, dashed-dotted dotted $\beta=10$ ). Bottom panel: percentage of variance of the decile variance accounted for by the common component: dashed $\beta=1$, dotted $\beta=4$, dashed-dotted dotted $\beta=10$ ). Deciles on the $x$-axis. 

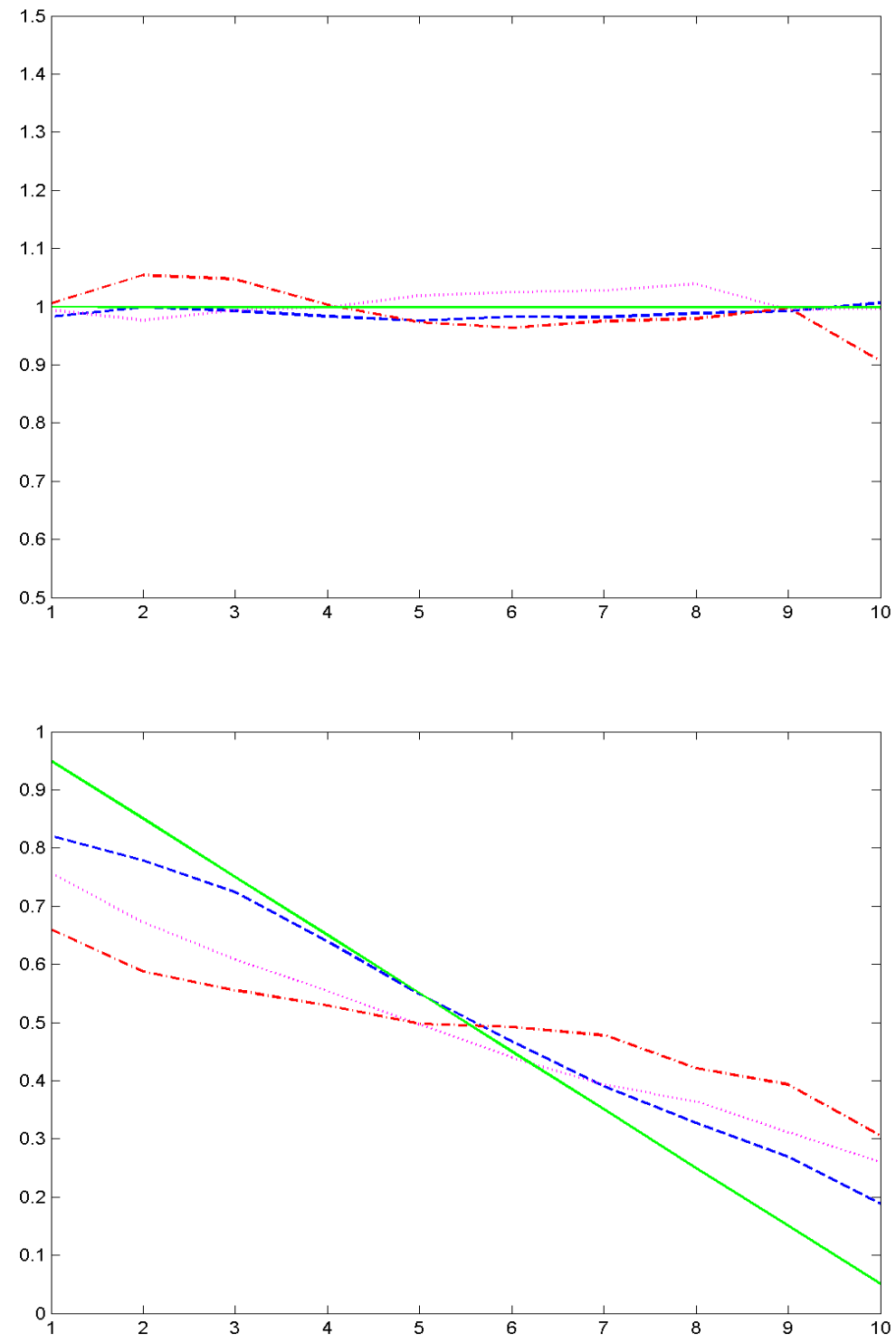

Figure 7. Top panel simulation \# 2. True mean values $a_{i}^{c}$ (solid line), and the estimated values $\hat{a}_{i}^{c}$, (dashed $\beta=1$, dotted $\beta=4$, dashed-dotted dotted $\beta=10$ ). Lower panel simulation \# 3. True mean values $a_{i}^{c}$ (solid line), and the estimated values $\hat{a}_{i}^{c}$, (dashed $\beta=1$, dotted $\beta=4$, dashed-dotted dotted $\beta=10$ ). 

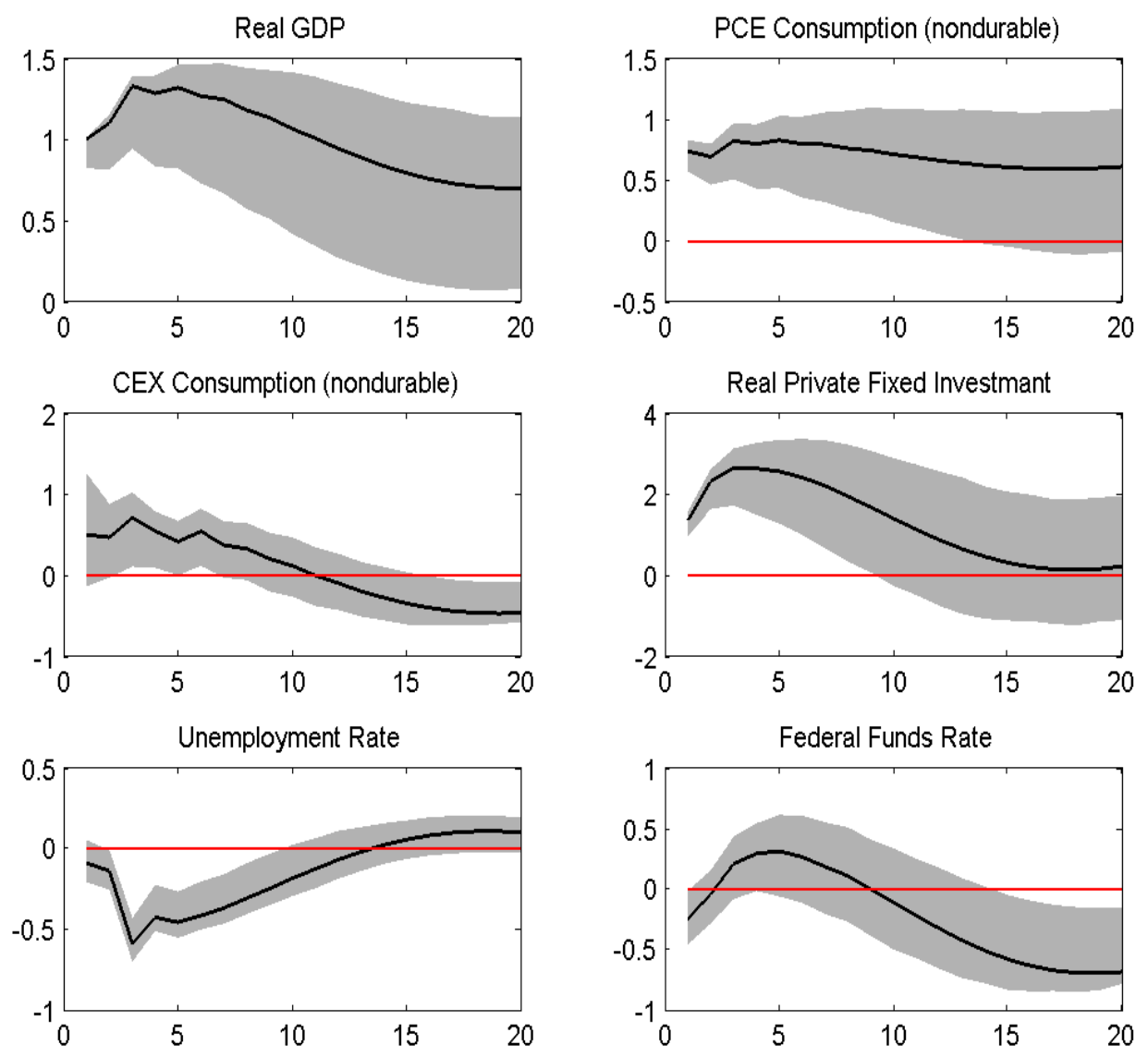

Figure 7. Impulse response functions of macroeconomic variables to a positive TFP shock. Solid line - point estimates; grey area - $68 \%$ confidence bands. 

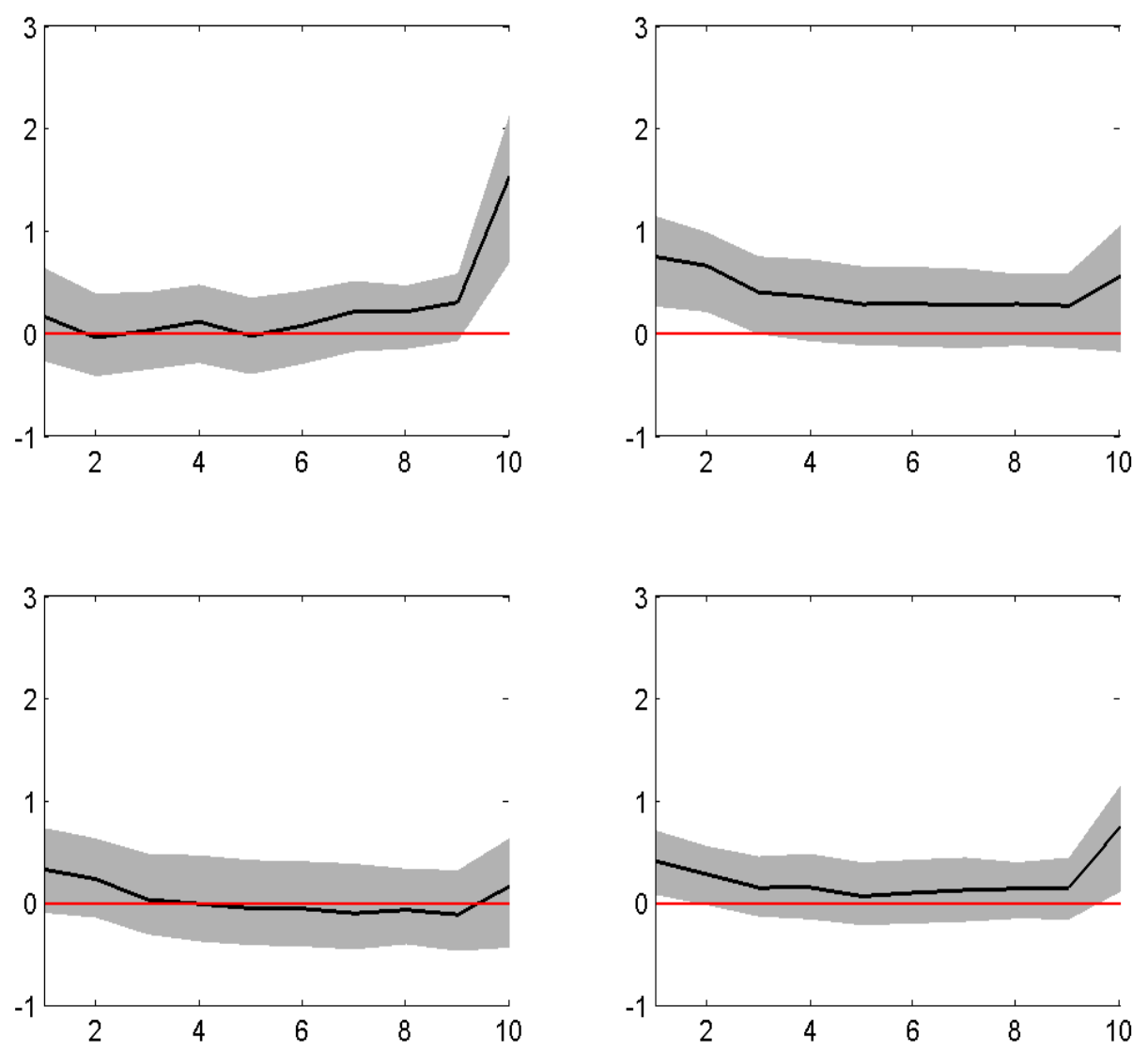

Figure 8. Impulse response functions of consumption deciles ( $x$-axis) to a positive TFP shock. The upper left panel - average effect over the first year after the shock. The upper right panel - effects over the second year. The lower left panel - average effects over the third year after the shock. The lower right panel - average effect over the first 3 years. Solid line - point estimates; grey area $-68 \%$ confidence bands. 

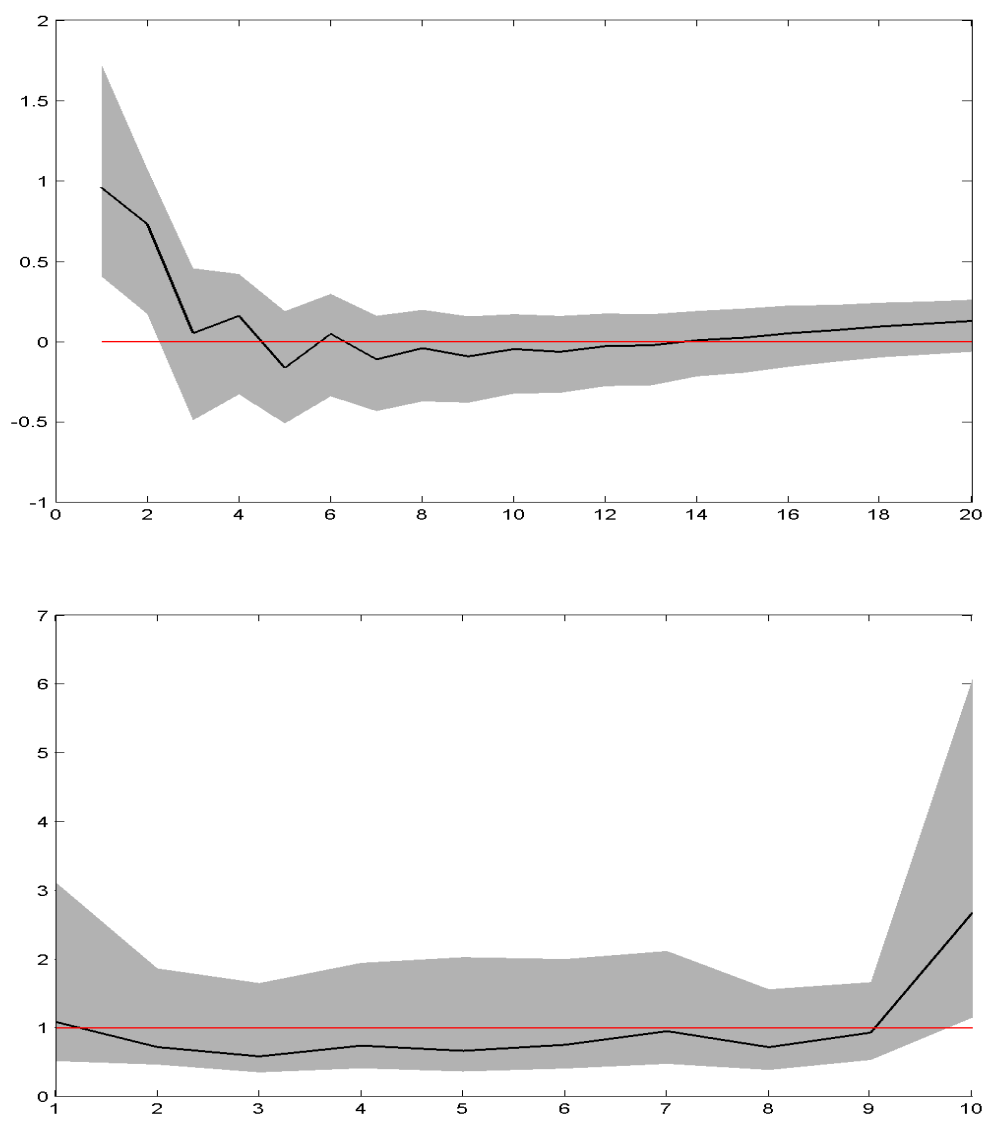

Figure 9. Top panel: response of inequality, measured as the difference between the response of the 10th decile and the 1st decile, to a TFP shock. Bottom panel: variance of each deciles attributable to the TFP shock rescaled by the variance of the CEX aggregate attributable to the TFP shock. Solid line - point estimates; grey area $-68 \%$ confidence bands. 

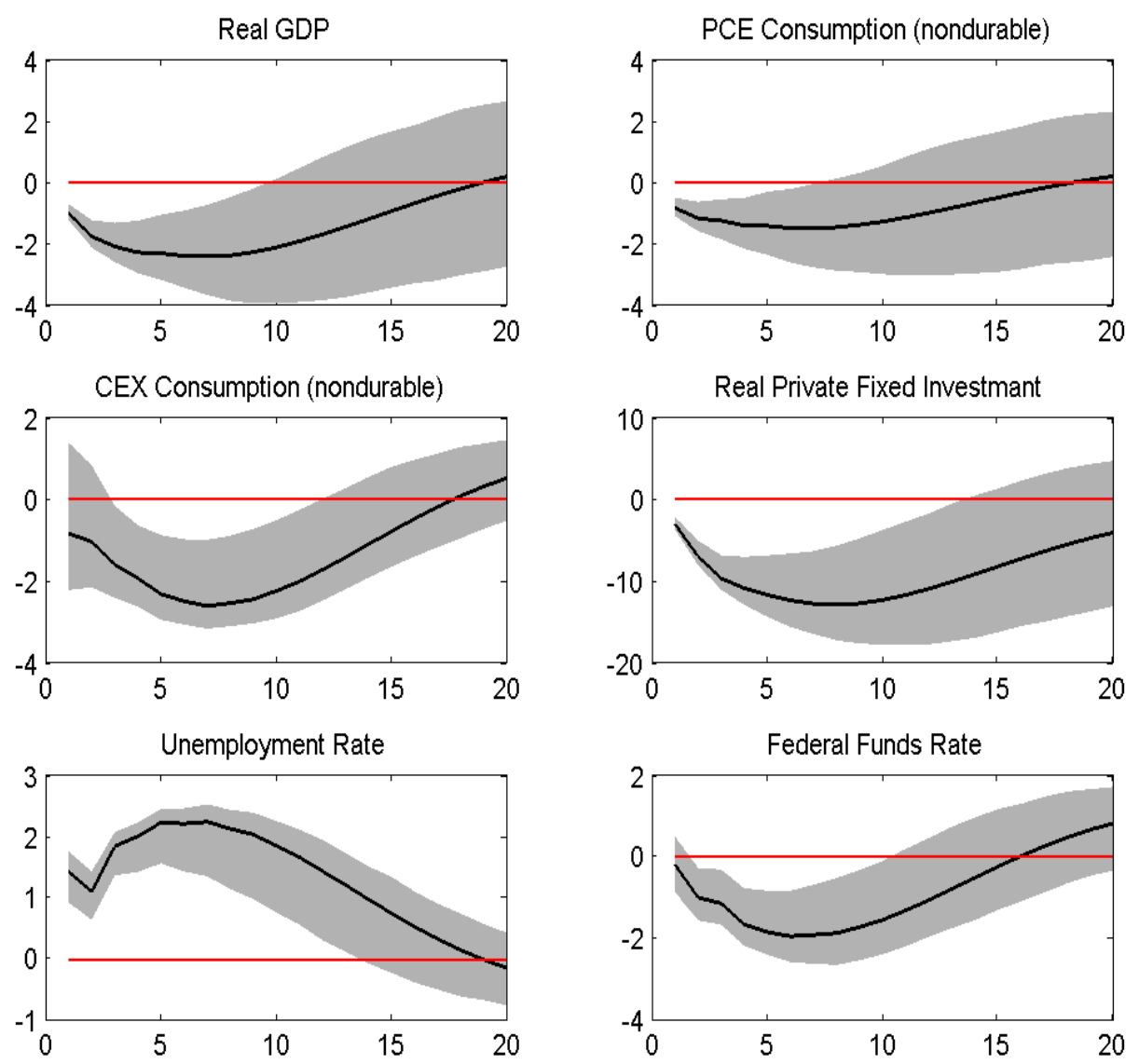

Figure 10. Impulse response functions of consumption deciles (x-axis) to en economic uncertainty shock. The upper left panel - average effect over the first year after the shock. The upper right panel - effects over the second year. The lower left panel average effects over the third year after the shock. The lower right panel - average effect over the first 3 years. Solid line - point estimates; grey area $-68 \%$ confidence bands. 

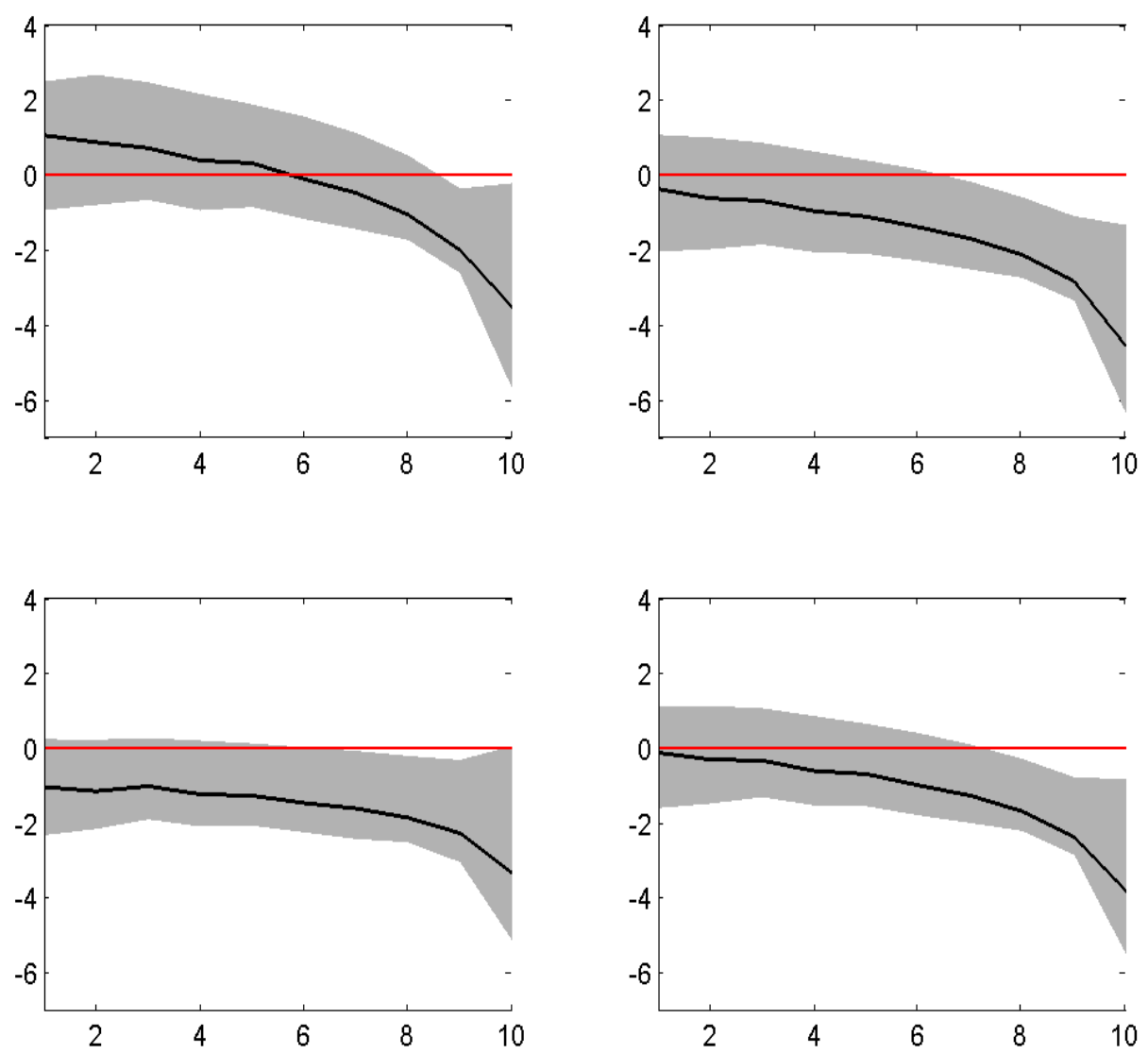

Figure 11. Impulse response functions of consumption deciles ( $x$-axis) to an economic uncertainty shock. The upper left panel - average effect over the first year after the shock. The upper right panel - effects over the second year. The lower left panel average effects over the third year after the shock. The lower right panel - average effect over the first 3 years. Solid line - point estimates; grey area $-68 \%$ confidence bands. 

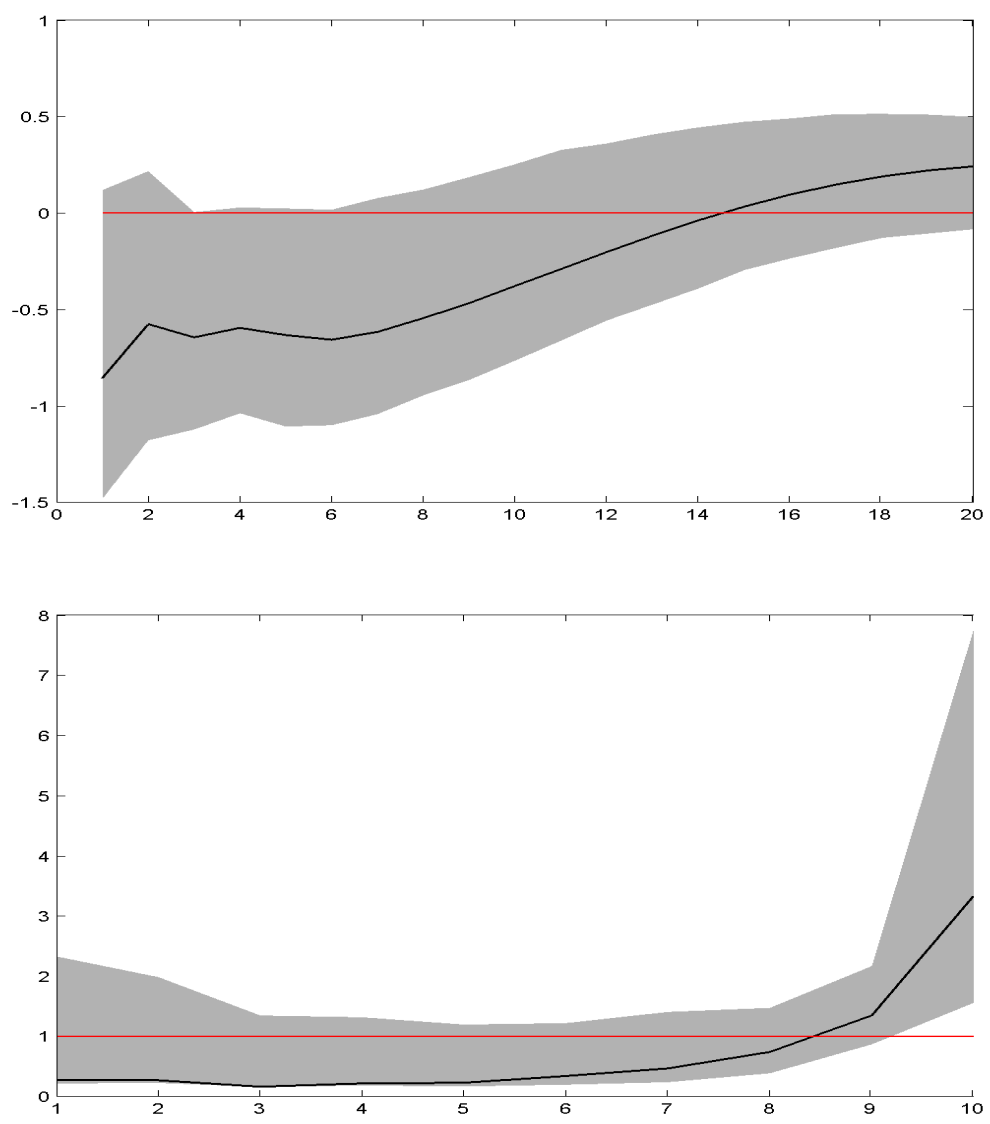

Figure 12. Top panel: response of inequality, measured as the difference between the response of the 10th decile and the 1st decile, to an economic uncertainty shock. Bottom panel: variance of each deciles attributable to the TFP shock rescaled by the variance of the CEX aggregate attributable to the TFP shock. Solid line - point estimates; grey area $-68 \%$ confidence bands. 

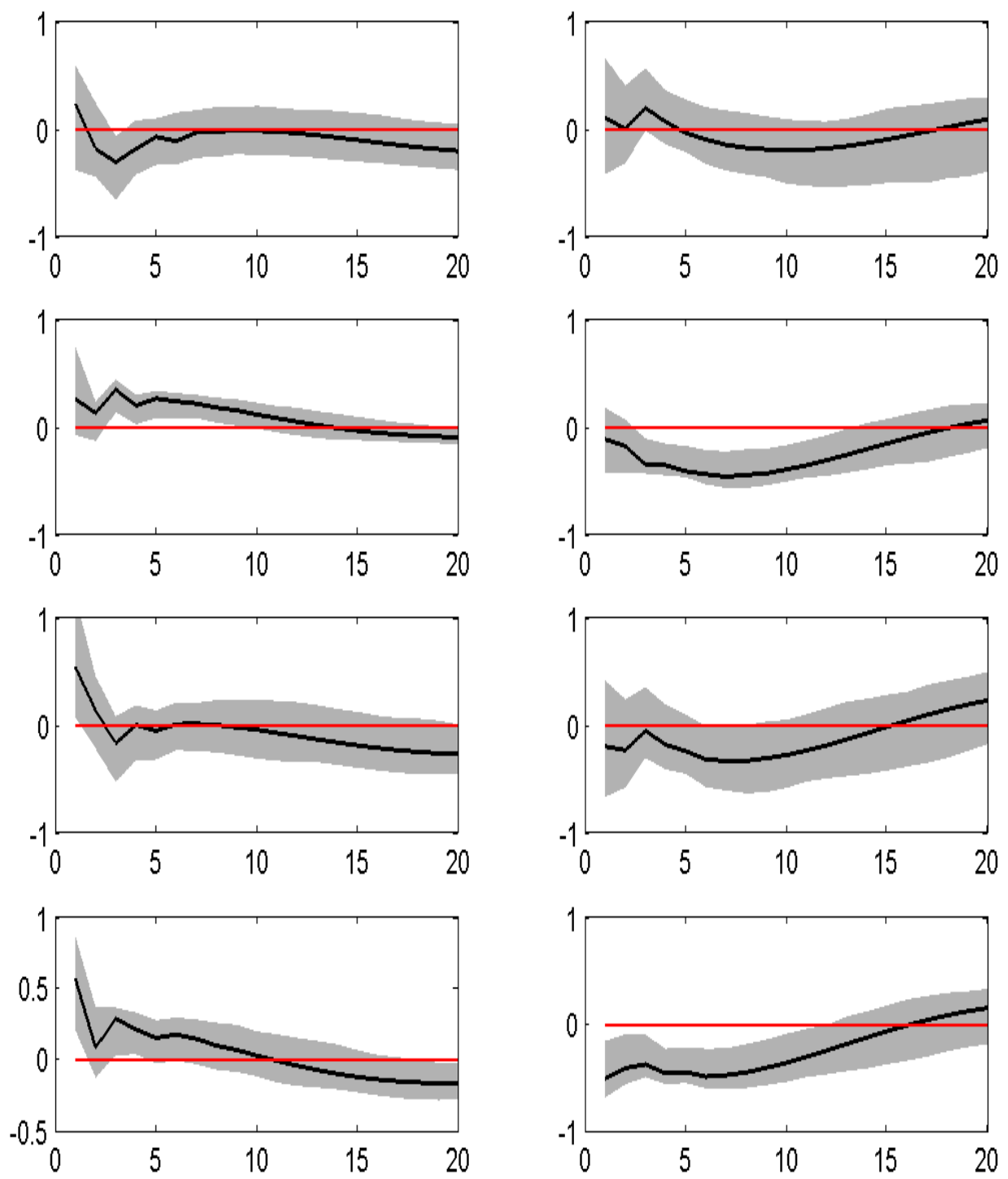

Figure 13. Impulse response functions of the four education categories to the TFP shock (left column) and economic uncertainty shock (right column). First row - less than high school (< HS); second row - high school (HS); third row - some college (Some col.); fourth row - college and graduate studies $(>=$ College). Solid line - point estimates; grey area $-68 \%$ confidence bands. 